\title{
Quantifying cerebral asymmetries for language in dextrals and adextrals with random-effects meta analysis
}

\author{
David P. Carey* and Leah T. Johnstone \\ Perception, Action and Memory Research Group, School of Psychology, Bangor University, Bangor, UK
}

\section{Edited by:}

Sebastian Ocklenburg, University of

Bergen, Norway

Reviewed by:

Kristiina Kompus, University of Bergen, Norway

Alan Alastair Beaton, Aberystwyth

University, UK

*Correspondence:

David P. Carey, Perception, Action and Memory Research Group,

School of Psychology, Bangor

University, Brigantia Building,

College Road, Bangor LL57 2AS, UK

e-mail:d.carey@bangor.ac.uk
Speech and language-related functions tend to depend on the left hemisphere more than the right in most right-handed (dextral) participants. This relationship is less clear in non-right handed (adextral) people, resulting in surprisingly polarized opinion on whether or not they are as lateralized as right handers. The present analysis investigates this issue by largely ignoring methodological differences between the different neuroscientific approaches to language lateralization, as well as discrepancies in how dextral and adextral participants were recruited or defined. Here we evaluate the tendency for dextrals to be more left hemisphere dominant than adextrals, using random effects meta analyses. In spite of several limitations, including sample size (in the adextrals in particular), missing details on proportions of groups who show directional effects in many experiments, and so on, the different paradigms all point to proportionally increased left hemispheric dominance in the dextrals. These results are analyzed in light of the theoretical importance of these subtle differences for understanding the cognitive neuroscience of language, as well as the unusual asymmetry in most adextrals.

Keywords: cerebral asymmetries, language, handedness, WADA test, laterality

\section{GENERAL INTRODUCTION}

The curious relationship between language-related asymmetries in the human brain and handedness was a fundamental question for neuropsychological and behavioral neuroscience over almost all of the twentieth century. Sadly, this question has become of more specialist interest in the last 20 years or so, as paradigms in the cognitive neuroscience of language become increasing less focused on questions related to the left and the right cerebral hemispheres. In parallel, during the 1970s and 1980s handedness researchers gradually became embroiled in methodological arguments over issues such as preference vs. performance, the precise definition of adextrality, and how measures of hemispheric specialization interact with fashionable covariates such as handwriting posture, sex, familial sinistrality, and so on. Because the relationship between handedness and language laterality is subtle (e.g., Baynes and Long, 2007), statistical differences between right handers and non-right handers are not always obtained, leading some scientists to conclude that these groups are effectively homogeneous with respect to cerebral asymmetry. Many studies, (in functional magnetic resonance imaging [fMRI] in particular), have avoided any controversy (or, theoretically, unnecessary additional variance) by restricting analysis to dextrals (e.g., Berlin et al., 1973; Lindell and Nicholls, 2003; Voyer and Ingram, 2005; Hirnstein et al., 2010). In others, differences between dextrals and adextrals are examined, but the results are often inconclusive about real differences. Tzourio-Mazoyer et al. (2014) report some subtle anatomical differences between dextrals and adextrals, but find no functional activation contrasts in a large sample. Szaflarski et al. (2012) find that adextral children are 85\% left brain dominant for language, hardly less than the dextral sample using their methods. Van der Hagen and colleagues argue that the effects of handedness on cerebral asymmetry are small, and suggest using direct measures of lateralization obtained from fMRI (see Van der Haegen et al., 2013b; also see Brysbaert, 1994).

This paper will attempt to reconcile evidence from several sources that all speak to the puzzling relationship between language dominance and dominant hand (particularly in the nonright handed, "adextral" population). In particular, we want to establish up to date estimates of any differences between dextrals and adextrals, comparing fMRI and other modern neuroscientific methods of the late twentieth and twenty-first centuries with the well-worn techniques of WADA testing, dichotic listening and visual half field experiments which dominated earlier in the twentieth century. To this end, we use meta analysis to try and establish whether there is a consistent difference between dextrals and adextrals, and if so, what is the best estimate for its magnitude, on average.

Several challenges are common across the diverse methods which examine language lateralization in individual people. Even within the specific paradigms outlined below, many studies differ in task, the reliability of the measurements, and the inclusion criteria for each group, in particular for the adextral sample. Within task, there is now some evidence to show that different strategies that individuals use can dramatically affect laterality quotients (for example, attentional biases/strategies may, and often do, muddy measurement of perceptual bias in dichotic listening experiments; Hugdahl and Andersson, 1986; Hugdahl et al., 2008; Hiscock and Kinsbourne, 2011). These direct attention blocks have also become very popular for experiments which help identify the relative contributions of bottom up and top 
down processes in auditory perception (Hirnstein et al., 2013; Passow et al., 2014).

Nevertheless, some of these concerns about between-study differences are less crucial if the data are treated meta-analytically. If some moderating variable, like sex or familial left handedness (Bishop, 1990), for example, is not balanced across two studies, differences in lateralization obtained may depend to an unknown degree on that unmeasured covariate. This sort of problem is lessened quite dramatically by an approach which produces a central tendency, rate ratio or effect size across many experiments (where presumably the distribution of the potential covariates will average out as simply another source of noise). In some sense, a multitude of studies which are heterogeneous, yet in spite of their differences, tend to point in the same direction when viewed collectively, is a strength rather than a weakness from a meta-analytic perspective.

Our working hypothesis for this set of studies is that all of the paradigms meta analyzed below will produce crudely equivalent group differences in proportions of left hemispheric speech/language dominance of approximately 15-20\%, favoring the dextral samples. For researchers interested in handedness, such a result would come as no surprise (Willems et al., 2014). Other scientists are less concerned about differences between dextral and adextral people (as the majority of both groups share direction of cerebral dominance, on average) or argue that handedness and cerebral dominance may be confounded with one another (Hervé et al., 2013). Perspective of the researcher may be relevant here: for an electrophysiologist studying a languagerelated waveform, exclusion of adextrals may be unnecessary for two reasons: adextrals are rare, (typically representing roughly $10 \%$ of the population), and in any case, most of them will be lateralized in a fashion similar to dextrals. Nevertheless, for many neuropsychologists, the relationship between handedness and cerebral asymmetry is real and needs explaining. In some sense, it is ironic that interest in handedness and asymmetry has waned as newer techniques (that the neuropsychologists of the 1970s could not have dreamed of) have been developed. Our goal in this paper is to help establish the most accurate estimates, on average, for left hemispheric dominance in dextrals and adextrals, and to suggest why these proportions are important for providing fresh impetus to this field.

\section{GENERAL MATERIALS AND METHODS}

Each of the paradigms/domains described below were systematically searched for papers that included estimates related to speech and language asymmetry for samples of dextral and adextral participants. Potential studies were selected from computerized databases (ScienceDirect, PubMed) and Google Scholar searches, as well as from the reference lists of all papers collected previously which met the inclusion criteria. We also relied quite heavily on related reference and cited reference searches. A few sources published in non-English languages were perused by colleagues for the relevant frequency data. In order to be included in the analysis, each study must have included dextral and adextral participants, and provided frequency data for those two groups on the dependent measures(s) related to cerebral asymmetry for language.
A "proportion" approach to the meta analytic procedures has been adopted, using frequency data for dextrals and adextrals rather than the more typical effect size measurements of differences in central tendency. A few papers using this latter kind of meta analysis have been conducted previously (language laterality and handedness: Kim, 1994; sex differences in handedness: Papadatou-Pastou et al., 2008). Such endeavors are useful in trying to establish whether there is a significant difference between dextrals and adextrals (or men and women) on a particular measure, but estimating average effect sizes of this sort cannot be unambiguously converted to estimates of incidences in groups of interest. Of course, groups may differ quite dramatically on some measure of central tendency, but the means and variances associated with those differences cannot unambiguously reveal how many individuals in each group showed a particular effect. These sorts of issues are explored in much more detail in the growing literature on individual differences, which tends to be rather critical about psychology's obsession with central tendency; see Kanai and Rees (2011), Vogel and Awh (2008), for some of the discussion.

In the particular case of hemispheric specialization, larger average asymmetries favoring dextrals are assumed to be due to a small number of the adextrals in the sample who are lateralized in the opposite direction (i.e., to the other hemisphere). Reduced asymmetries in many or all of the individuals in an adextral sample would require a rather different interpretation. In fact, comparing different measures of a hypothetical underlying construct will be facilitated if the proportions of each group showing a typical pattern are reported. This approach may also circumvent some of the difficulties with test-retest reliabilities of some measures of language-related asymmetry such as dichotic listening (see General Discussion).

One particular difficulty in comparing the different studies summarized in the meta analyses of this paper is that many of them use quite distinct criteria for assigning individuals to operationally-defined dominance groups. For example, many (but not all) studies opt for a "bilateral" or "no difference" category when measured asymmetries between visual fields in tachistiscopic tasks, ears in dichotic listening tasks, or hemispheres in the case of fMRI, do not exceed a pre-specified threshold of lateralization (discussed in Jansen et al., 2006; Seghier, 2008). This problem is circumvented here by grouping together bilateral and no difference groups with those who display asymmetries favoring the right hemisphere on a language task ${ }^{1}$.

All meta analyses were performed using MetaXL, developed by Barendregt and colleagues, available as freeware from http://www.epigear.com/index_files/metaxl.html.

For all the analyses a rate ratio meta analysis was used (these are referred to as risk ratios in some studies, including Experiment 1 on aphasia incidence). These compare the proportion of people in one binomial category to those in the other, and compare

\footnotetext{
${ }^{1}$ We have used the term "anomalous dominance" here for right brain dominance, bilateral or no dominance categories in any particular study. The term is not intended to presuppose that non-left dominance is somehow pathological, as implied by the "Geschwind-Behan-Galaburda" model of the 1970s (see Bryden et al., 1994; Dellatolas, 1994, for detailed discussion).
} 
this proportion in two separate groups. Statistically, odds ratios, rather than rate ratios, have more attractive mathematical properties for this kind of analysis, such as symmetry about "no difference" in an effect. However, for the frequency data for all the techniques described below, there was no theoretical reason to suspect any differences in the "other" direction-e.g., adextrals being more susceptible to aphasia after left lesions than dextrals; more adextrals with right ear advantages, etc. Finally, rate ratios are easier to interpret.

All available studies for each paradigm were subjected to a random effects meta analysis (using the variance estimators recommended by DerSimonian and Laird, 1986). These techniques allow for statistical estimates of central tendency (as effect sizes, means, rate ratios and so on) and variability to be made across a number of different studies which examine similar dependent and independent measures. Fixed effects models assume that each individual study is sampling the same underlying population effect and that all variance from study to study is measurement noise, sampling error, subtle differences in test administration and so on. Random effects do not assume that all of the underlying studies sample an identical population effect (Haddock et al., 1998; Borenstein et al., 2010; Cumming, 2012); hence there are sources of variation (say, aphasia as classified by different measures in samples tested at slightly different times after the neurological insult, etc.), which will not be identical from study to study. One limitation of random effects methods, however, is that studies with smaller sample sizes can contribute more to the overall effect estimate, as they contribute more to estimates of between study variability - in fixed effects models smaller variances result in larger weights). Nevertheless, the rate ratios from fixed and random effects models will be very similar when the heterogeneity is small, so we favor the more conservative approach of random effects.

For the subsequent paradigm-specific meta analyses, differences in precise tasks used, sex of group members, cut-off procedures, how adextrals were recruited, sampling bias and so on, make it quite clear that a random effects analysis is appropriate. Having said that, these studies are all attempting to estimate, directly or indirectly, differences in hemispheric specialization related to language processing. Studies too numerous to mention have identified the non-perfect relationships between these different techniques (and at times some rather limited test-retest reliabilities) so will not be discussed further (but see Bryden, 1982; Brysbaert, 1994; Binder, 2011 for further discussion of many of the most pertinent issues).

\section{META ANALYSIS 1: APHASIA INCIDENCE AFTER UNILATERAL BRAIN DAMAGE INTRODUCTION}

Most of the early research which addressed language lateralization and handedness depended on studies of aphasic disturbances in individuals (Critchley, 1954). Early attempts to link right hemispheric language lateralization to left hand preference for writing (lumped together, erroneously, in fact, as "Broca's rule" e.g., Eling, 1984; Harris, 1991) were discredited quite quickly in the late nineteenth and early twentieth century (Harris, 1991). Case studies, too numerous to review here, have documented examples of "crossed" aphasia and apraxia in single individuals (e.g., aphasia or apraxia after a right hemisphere lesion in a right hander or, much more rarely described, the left hemisphere in a left hander; reviewed in Alexander and Annett, 1996; Coppens et al., 2002). As important as these single cases studies were, it was the large sample studies of aphasia and handedness that debunked the idea of a perfect link between hand preference and a speech-dominant contralateral hemisphere.

These rather laborious group studies of hospital patients with and without aphasia were the first datasets that suggested that right hemispheric dominance in adextrals was not the norm by any stretch of the imagination. Unfortunately, the accuracy of estimates from this research is complicated by the anti-sinistral biases that were common, even in Western cultures, for anyone born prior to World War 2. Inevitably, some proportion of lefthanded writers will have been forced to switch their handedness at an early age. Similarly, "left handers" in such cohorts were probably those individuals most resistant to direct or indirect pressures to switch to the preferred right hand (this topic is reviewed in Siebner et al., 2002; Searleman and Porac, 2003) Considering the average age of many stroke patients, these sources of bias will have had persisting effects well into the twentieth century. Unfortunately, dissipation of such effects is happening too late, as such large sample studies have become more expensive and less fashionable. In some of the early experiments, heroic efforts were made to document cases of handedness switch in some "right" handers (e.g., Gloning, 1977), but these were the exception rather than the norm.

For inclusion in this analysis, three criteria needed to be met. First, aphasia incidence needed to be estimated in groups of dextrals and adextrals using the same tests and criteria. Second, the number or proportion of dextrals and adextrals who were so diagnosed out of larger samples of unilateral brain damage was reported. Finally, we expected no admission or strong suggestion of pre-selection of non-right handers in any way that would bias estimates of aphasia frequency after left or right brain damage (see below).

\section{METHODS}

Literature searches in Pubmed revealed 1100 sources when "aphasia" and "handedness" were searched for (September, 2014). Many of these studies: (1) only provide the mean handedness of an exclusively dextral sample; (2) are single case reports; and (3) compare treatments of right and left handed dysphasics. Additional potential studies were sourced by cited reference searches of early papers on aphasia in adextrals including Basso et al. (1989, 1990), Brain (1945), Critchley (1954), Goodglass and Quadfasel (1954), Humphrey and Zangwill (1952), Zangwill (1960).

Unfortunately, several large scale studies of aphasia incidence do not report handedness (e.g., Laska et al., 2001; Chilosi et al., 2005) or do not report their data by side of lesion and handedness, as well as by presence or absence of aphasia (e.g., Bingley, 1958; Zangwill, 1960; Brown and Hécaen, 1976; Hécaen, 1976; Vargha-Khadem et al., 1985; Basso et al., 1990; Pedersen et al., 1995, 2004; Basso and Rusconi, 1998; Godefroy et al., 2002). For example they may report how many aphasics in a subgroup 
were right or left handed, but these sorts of data are not sufficient, without information about how many patients with left or right unilateral lesions were not aphasic. An additional restriction in this literature is that it has gradually shifted into looking for functional evidence for compensation in dysphasics within a damaged hemisphere or in the contralateral (presumably innately non-dominant) hemisphere. These newer studies often have small samples, and examine right-handed patients only which almost inevitably means lesions of the left hemisphere (e.g., Pettit and Noll, 1979; Heiss et al., 1999; Duffau et al., 2003; Krieg et al., 2013).

An additional methodological concern (as if there aren't enough already) in studies of aphasia incidence and handedness is that the earliest (and best cited) papers are not, in fact, composed of samples of unselected dextrals and adextrals with unilateral brain damage. Instead they are typically "compilations of scattered individual cases" (Kimura, 1983), where non-right handers were particularly noteworthy when they presented with aphasia, and not so noteworthy when they did not. For this reason one of the best known studies (Goodglass and Quadfasel, 1954) has been excluded from the analyses. In other experiments, inclusion criteria for individual patients included "adequate tests for aphasia” (Humphrey and Zangwill, 1952), which as Kimura (1983) notes, implies that some dextral and or adextral patients were not routinely tested. We have excluded this source as well.

Studies of unselected series of left and right brain damaged patients, which also recorded handedness are remarkably rare. As Kimura (1983) reports in one of the most cogent analyses, some selectivity (not necessarily described in the manuscript or book) of adextral cases is the norm rather than the exception (see also Annett, 1975, 2002). Nevertheless, we managed to identify 14 such studies, which are the subject matter of the first two meta analyses.

\section{RESULTS}

The 14 studies of patients with left brain damage summarized included 2421 dextral and 390 adextral patients; the 13 studies $^{2}$ of patients with right brain damage summarized included 1907 dextral and 256 adextral patients. The results of this analysis on aphasia incidence are plotted in Figure 1. (Supplementary Material contain the excel spreadsheets for this analysis, which provide the raw frequencies for dextrals and adextrals, the weights of each study in the final rate ratio estimate, and so on). In the top panel, the effects of unilateral left hemisphere lesions are depicted, comparing risk ratios calculated for dextral and adextral patients (in that order). A risk ratio in this context contrasts the number of unilateral brain damaged patients with aphasia to those without aphasia; this proportion in dextrals serves as the numerator to the same proportion in adextrals (therefore risk ratios greater than one indicate greater sensitivity in dextrals).

The associated Q statistic $(62.52, p<0.001)$ for aphasia after left brain damage suggests considerable heterogeneity across studies (which validates the use of a random, rather than a

\footnotetext{
${ }^{2}$ The precise numbers of dextral and adextral patients screened after right brain damage were not available in Luria (1970), hence its exclusion from the second but not the first analysis.
}

fixed-effects analytical strategy). $\mathrm{I}^{2}$, another measure, provides the percentage of total variance due to variation between studies. The pooled risk ratio suggests that there are no differences between dextrals and adextrals in terms of their susceptibility to aphasia after unilateral left hemisphere lesions: risk of 1.03 (95\% C.I. $=0.83-1.27)$. These same data were heterogeneous across study $\left(I^{2}=79.21\right)$.

By contrast, the pooled risk ratio following right hemisphere lesions suggests a clear difference (bottom panel), although a considerably noisy one: odds of 0.15 (95\% C.I. $0.05-0.44 ; I^{2}=$ 92.31) were obtained one. Stated in terms of adextral relative to dextral susceptibility, the risk ratio is 6.7 for adextrals to become dysphasic after a right hemisphere lesion relative to the dextral population. As with the left brain damage analysis above, perhaps unsurprisingly, heterogeneity of these estimates is large: $Q=156.02, p<0.001$. Many studies not included in the meta analysis quantify aphasia incidence in dextrals after left or right hemispheric damage. These studies result in a similar bias toward greater aphasia incidence after left hemisphere lesions (e.g., McGlone, 1977; Wade et al., 1986).

\section{DISCUSSION}

The noisiness of both of these overall effects is partly due to the sample sizes available, for the adextral patients in particular (e.g., adextral n's range for left lesions from 6 to 87; Supplementary Material; for right lesions from 2 to 53; Supplementary Material). Annett $(1975,2002)$ argues that the series also have different proportions of left handers, which shows different inclusion criteria, which will lead to different distributions of speech lateralization. In spite of this heterogeneity, these data suggest that dextrals and adextrals are similarly prone to aphasia after left hemisphere lesions, and that right hemisphere lesions are much more likely to produce dysphasia of some sort in adextrals compared to dextrals. It is tempting to relate the similarity of the two handedness groups in susceptibility to dysphasia after left lesions to statistical noise plus the considerable evidence suggesting that adextrals are largely left brained for language, as are the dextrals, of course. Nevertheless, the lack of even a small difference favoring increased incidence in the dextrals is puzzling. Sample size clearly is at issue here, but the samples for the second meta analysis (patients with right brain damage) are similarly limited. The absence of aphasic symptoms in people with left hemisphere damage might mean that they don't present to neurologists or stroke specialists who compile some of these group studies (Levy, 1974; Annett, 2002)_perhaps more of an issue for adextrals after left hemisphere lesions (relative to dextrals), but such selectivity could also affect incidence estimates for aphasia in dextrals after right lesions.

Nevertheless, this meta analysis does suggest that dextrals and adextrals do not differ in terms of susceptibility to aphasia after left hemispheric lesion. Few of the investigators of the original studies have commented on this particular symmetry. In part, the absence of a difference in many of the papers was interpreted in terms of refuting "Broca's rule"-what was noteworthy at the time was that the adextrals were not right brained for language. Comment on their striking similarity to dextrals is infrequent. 


\section{Aphasia after left brain damage}

Study

Weisenberg \& McBride (1935)

Conrad (1949)

Critchley (1954)

Zangwill (1954)

Hecaen and Percy (1956)

Bingley (1958)

Penfield \& Roberts (1959)

Hecaen \& Ajuriaguerra (1964)

Luria (1970)

Newcombe \& Ratcliff (1973)

Gloning (1977)

Bryden, Hecaen \& DeAgostini (1983)

Hecaen (1983)

Kimura (1993)

Overall

$Q=62.52, p=0.00,12=79 \%$
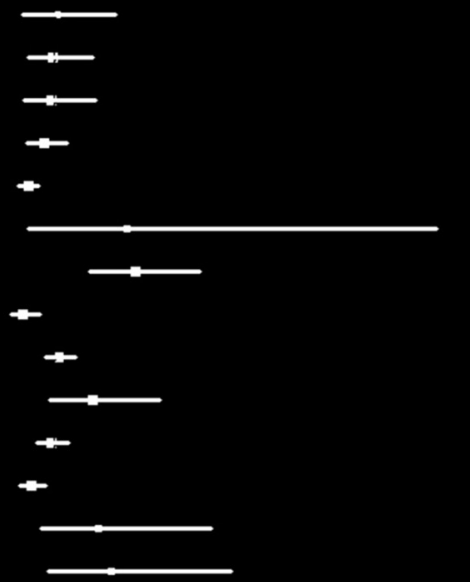

RR $(95 \% \mathrm{Cl}) \quad$ \% Weight

$1.03(0.57,1.85) \quad 5.69$

$0.98(0.63,1.53) \quad 7.10$

$0.96(0.59,1.57) \quad 6.63$

0.85 ( $0.62,1.17) \quad 8.33$

$0.63(0.51,0.78) \quad 9.30$

$2.02(0.65,6.31) \quad 2.56$

$2.13(1.50,3.03) \quad 8.00$

$0.57(0.40,0.80) \quad 8.08$

$1.07(0.88,1.30) \quad 9.42$

$1.53(0.95,2.46) \quad 6.71$

$0.96(0.77,1.20) \quad 9.21$

$0.68(0.52,0.88) \quad 8.91$

$1.62(0.82,3.19) \quad 4.97$

$1.79(0.92,3.47) \quad 5.09$

$1.03(0.83,1.27) \quad 100.00$

Aphasia after right brain damage Study

Weisenberg \& McBride (1935) -

$\operatorname{RR}(95 \% \mathrm{Cl}) \quad$ \% Weight

Conrad (1949) -

Critchely (1954)

Zangwill (1954) •

Hecaen \& Percy (1956) -

Bingley (1958) -

Penfield \& Roberts (1959)

Hecaen \& Ajuriaguerra (1964)

Newcombe and Ratcliff (1973) $\quad-$

Gloning (1977) -

Bryden, Hecaen \& DeAgostini (1983) $\rightarrow$

Hecaen (1983)

Kimura (1993)

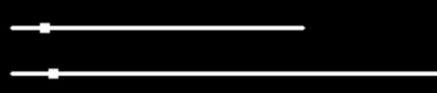

$0.06(0.01,0.30) \quad 7.91$

$0.11(0.05,0.26) \quad 8.90$

$0.31(0.02,3.81) \quad 6.31$

$0.01(0.00,0.04) \quad 7.83$

$0.17(0.07,0.40) \quad 8.86$

$0.04(0.00,0.39) \quad 6.85$

$0.05(0.00,0.51) \quad 6.56$

$2.86(1.99,4.12) \quad 9.26$

$0.25(0.12,0.52) \quad 8.97$

$0.02(0.00,0.35) \quad 5.93$

$0.26(0.10,0.66) \quad 8.78$

$0.38(0.05,2.92) \quad 7.08$

$0.46(0.05,4.27) \quad 6.78$

Overall

$0.14(0.05,0.44) \quad 100.00$

$Q=156.02, p=0.00,12=92 \%$

$\begin{array}{lllll}0 & 1 & 2 & 3 & 4\end{array}$

RR

FIGURE 1 | Random effects meta analyses of relative risk of aphasia after unilateral brain damage, dextrals compared to adextrals. Risk ratios greater than one suggest greater susceptibility of dextrals than adextrals; less than one greater susceptibility of adextrals than dextrals. $\mathrm{Cl}=95 \%$ confidence intervals. $\mathrm{I}^{2}$ is a measure of the percentage of total variation due to variation between studies. Note that no estimates of susceptibility were provided in Luria (1970) for right hemisphere lesions. Top panel: unilateral left brain damage. Bottom panel: unilateral right brain damage. For additional comments and the raw frequencies, for all figures, see Supplementary Materials. 
As an aside, some of these early aphasia studies also suggested two parallel but slightly counterintuitive hypotheses about aphasic syndromes in non-right handers. First, Chesher (1936) and Gloning et al. (1969) provided early evidence to show that adextrals were more likely to have dysphasia after brain damage than dextrals (see also Hécaen and Percy, 1956; Satz et al., 1965; Satz, 1979; although Newcombe and Ratcliff, 1973; Kimura, 1983; contest these claims). Second, comparing prognosis in right and non-right handers after becoming dysphasic, the adextrals tend to recover somewhat earlier and more completely (Subirana, 1969; although this claim is also contentious, see Pedersen et al., 1995). These somewhat contradictory findings are in part more understandable (at least) when data from large scale studies of another group of patients began appearing in the 1960s and ideas of bilateral speech representation, in adextrals at least, became more commonly understood. It is also tempting to relate the first claim to the current findings; similar dysphasia risk after left lesions but increased risk after right lesions.

\section{META ANALYSIS 2: WADA TESTING IN PRE-SURGICAL EPILEPTIC PATIENTS INTRODUCTION}

Another class of neuropsychological data, distinct from the laborious large sample aphasia incidence studies, has come to dominate thinking about language lateralization and handedness (and unlike the aphasia studies, such experiments continue to be performed to this day). Juhn Wada popularized a technique for determining language lateralisation in pre-surgical candidates for epilepsy surgery (Snyder and Harris, 1997; Wada, 1997). A great advantage of anesthetizing each hemisphere in turn and testing for speech arrest is that participants could be classified trichotomously (left hemisphere dominant; right hemisphere dominant, or bilateral). Bilateral classification was a consequence of either no speech arrest after amytal to either hemisphere (a type one of us refers to students as "good bilateral") or speech arrest after amytal to either hemisphere ("bad bilateral"). Some researchers claim that speech arrest in these later cases can be somewhat less severe than what is typically obtained from patients with epilepsy with more straightforward unilateral speech dominance.

In any case, this technique, in the capable hands of Milner, Rasmussen, Penfield and others at the Montreal Neurological Institute, led to the most popular estimates of speech lateralization in dextrals and adextrals (see Table 1). This popularity is somewhat surprising, as of course, most people with intractable epilepsy would have had brains that had dealt with congenital abnormalities for a lifetime; perhaps not the most representative sample for asymmetry estimation in the neurologically-intact brain $^{3}$.

Since these early observations, large scale studies using the WADA test have been published on several occasions. The availability of these large $\mathrm{n}$ datasets is made possible by the tremendous popularity of the technique in neurosurgery units, even

\footnotetext{
${ }^{3}$ For reviews of neural plasticity as a function of age, see Dennis (2000). Early left hemispherectomy often results in right hemispheric language dominance, which in many ways resembles the typical functional organization of language in the left hemisphere (Staudt et al., 2002).
}

Table 1 | Trichotomous classification of speech and language dominance in 266 epileptic patients using the WADA test (Rasmussen and Milner, 1977).

\begin{tabular}{lccc}
\hline & \multicolumn{3}{c}{ Speech lateralization } \\
\cline { 2 - 4 } & $\begin{array}{c}\text { Left hemisphere } \\
(\%)\end{array}$ & $\begin{array}{c}\text { Bilateral } \\
(\%)\end{array}$ & $\begin{array}{c}\text { Right hemisphere } \\
(\%)\end{array}$ \\
\hline GROUP & & & \\
Dextrals & 96 & 0 & 4 \\
Adextrals & 70 & 15 & 15 \\
\hline
\end{tabular}

after fMRI availability had become widespread (Baxendale et al., 2008; Wagner et al., 2012). These studies, often with more refined techniques and definitions, are subject to the caveat of potentially abnormal hemispheric lateralization in people with congenital brain abnormalities (Kimura, 1993; Annett, 2002). Nevertheless, the estimates for the most part are largely consistent with the Rasmussen and Milner percentages presented in Table 1. Literature searches revealed 350 (partially overlapping) sources when ("WADA" or "IAT" or "sodium amytal") and "handedness" were searched for in PubMed (September, 2014). Additional potential studies were sourced by cited reference searches of early papers on WADA and handedness including Binder et al. (1996), Rasmussen and Milner (1977), Woods et al. (1988) or came up in our other PubMed and Google scholar searches.

\section{RESULTS}

The 32 studies summarized included 2771 dextral and 738 adextral patients. The results of the random effects meta analysis of these studies appears in Figure 2. Supplementary Material contains the associated Excel file with the raw data, weights for each study and a description on a separate sheet of some of the studies checked but not included in the analysis. In this comparison, unlike in the aphasia incidence meta analyses above, dextrals and adextrals are compared in one analysis, which contrasts the risk ratios (in this case some investigators would refer to it as a rate ratio) of left brain dominance relative to anomalous dominance for speech. In this latter category, in the studies where bilateral dominance was occasionally assigned, these cases were pooled with right brain dominance (this convention is also followed in Figures 3, 4 for the dichotic listening [DL]/visual half field [VHF] data and the fMRI/ECT/TDS data, respectively).

These data, collectively, contain less heterogeneity across studies $\left(Q=43.54, p<0.07 \mathrm{NS} ; I^{2}=28.81 \%\right)$ than the aphasia meta analyses above. The rate ratios for $30 / 32$ studies are greater than 1 (range 0.93-3.00). The overall rate ratio is 1.36 (95\% CI $1.26-$ 1.46). These data suggest that left brain dominance, at least in epileptic patients selected for and assessed using the WADA test, is more common in dextral populations than adextral ones.

We also modeled \% left dominance in the two groups by weighting each group percentage (n left dominant/n left dominant $+\mathrm{n}$ anomalous dominance ${ }^{*} 100$ ) by the meta-analytically derived inverse weighting (See "weighted means" columns in Supplementary Materials). This procedure suggests a best estimate, on average, of left brain dominance in dextrals of $87 \%$ and 


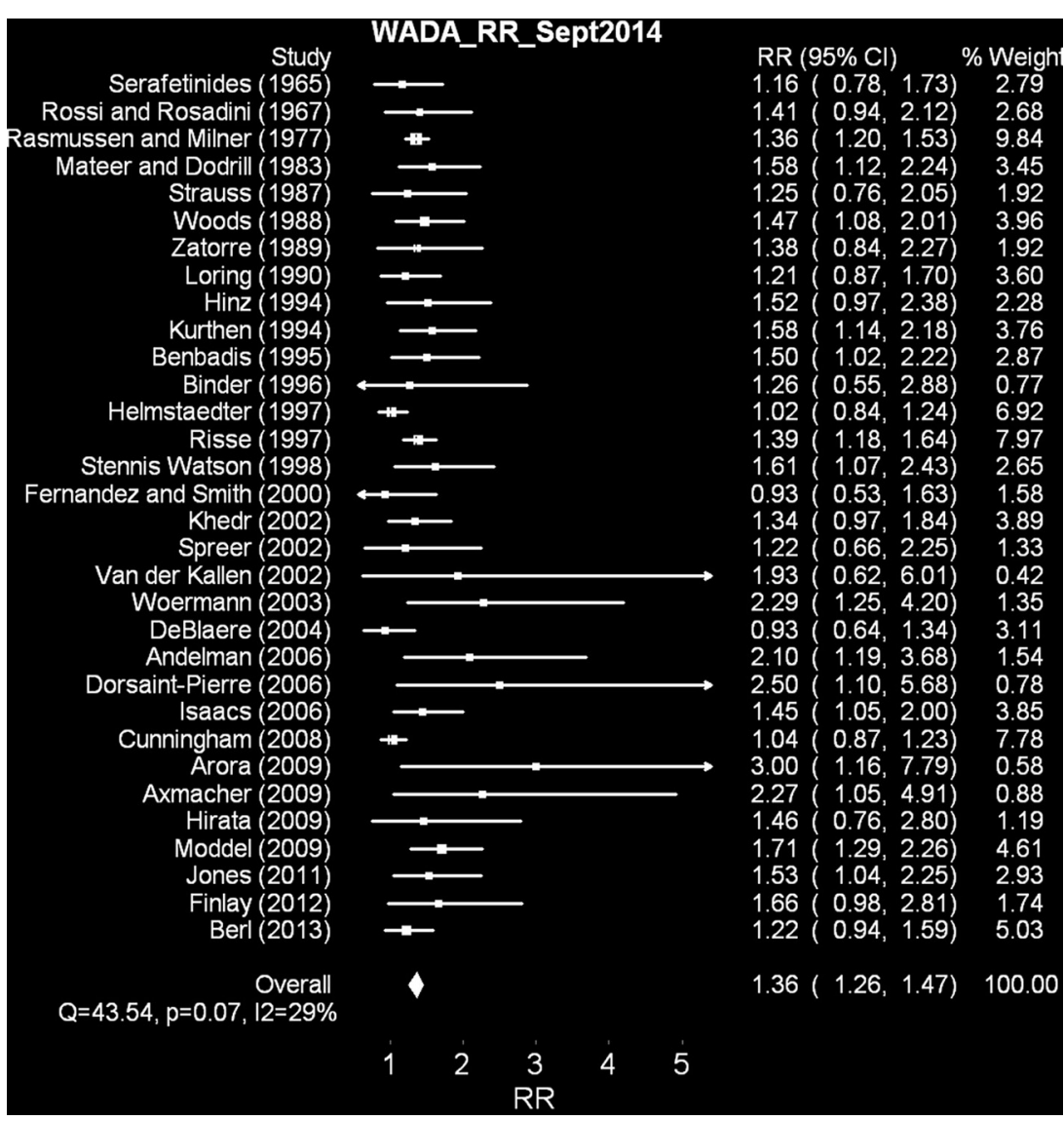

FIGURE 2 | Random effects meta analysis of WADA test left brain dominance relative to anomalous dominance for dextrals relative to adextrals. Note that the range of the $95 \%$ confidence intervals for the overall effect, does not overlap zero.

in adextrals, 65\%). The former proportion is not radically different from other studies that report WADA data from large dextral samples only (e.g., Benbadis et al., 1995b; see Ocklenburg et al., 2014 for a recent review; also see more rare adextral-only studies such as Perlaki et al., 2013).

\section{DISCUSSION}

These results point to increased left hemisphere dominance in dextrals relative to adextrals, in contrast with the left brain damage aphasia incidence data reported in Meta Analysis 1. Of course, there are many scientific caveats related to these samples, most of which are distinct from those related to the aphasia incidence data analyzed above. For example, there is some debate about how to classify individuals as bilateral for speech (surprising, in that a binary speech arrest yes/no classification should be possible after WADA testing; for reviews see Snyder et al., 1990; Baxendale, 2002). For example, Benbadis et al. (1995a) contrast this "arrest, yes or no" kind of approach with duration of speech arrest and relative speech criteria (i.e., L-R/L+R, a type of normalizing laterality quotient much more common in the dichotic listening literature mentioned below). When they adopted $2 / 3$ of these measures to indicate bilateral representation, they could group these patients into bilateral autonomous (either hemisphere on its own can support speech) and bilateral dependent (both hemispheres show equivalent speech arrest). This proportion was roughly 50:50 (but only 19/165 patients achieved classification as bilateral with this set of criteria). They did not find much of a difference between the proportions of dextrals and adextrals in either bilateral or right dominance groups.

The current results suggest more dramatic differences between dextrals and adextrals (in the case of the left hemisphere in particular) than in the aphasia incidence literature summarized in Figure 1. One problem for estimating hemispheric asymmetry in non-epileptics from these studies is that, of course, many people suffering from severe epilepsy will have had congenital abnormalities, which may in some instances at least, lead to a change in speech and language dominance from one hemisphere to another. Of course, this caveat should apply to the estimates of speech dominance in the dextrals as well as the adextrals (assuming, probably wisely, that epileptogenic foci are rather agnostic about which hemisphere they choose to appear in), unless of course a more complicated "pathological left handedness" argument is made (e.g., Geschwind and Galaburda, 1985a,b,c). Claims for increased incidence of adextrality in epilepsy are extremely common. For example, Kim et al. (2001) claim a 15\% incidence of left handedness in a sample of Korean epileptic patients with left 


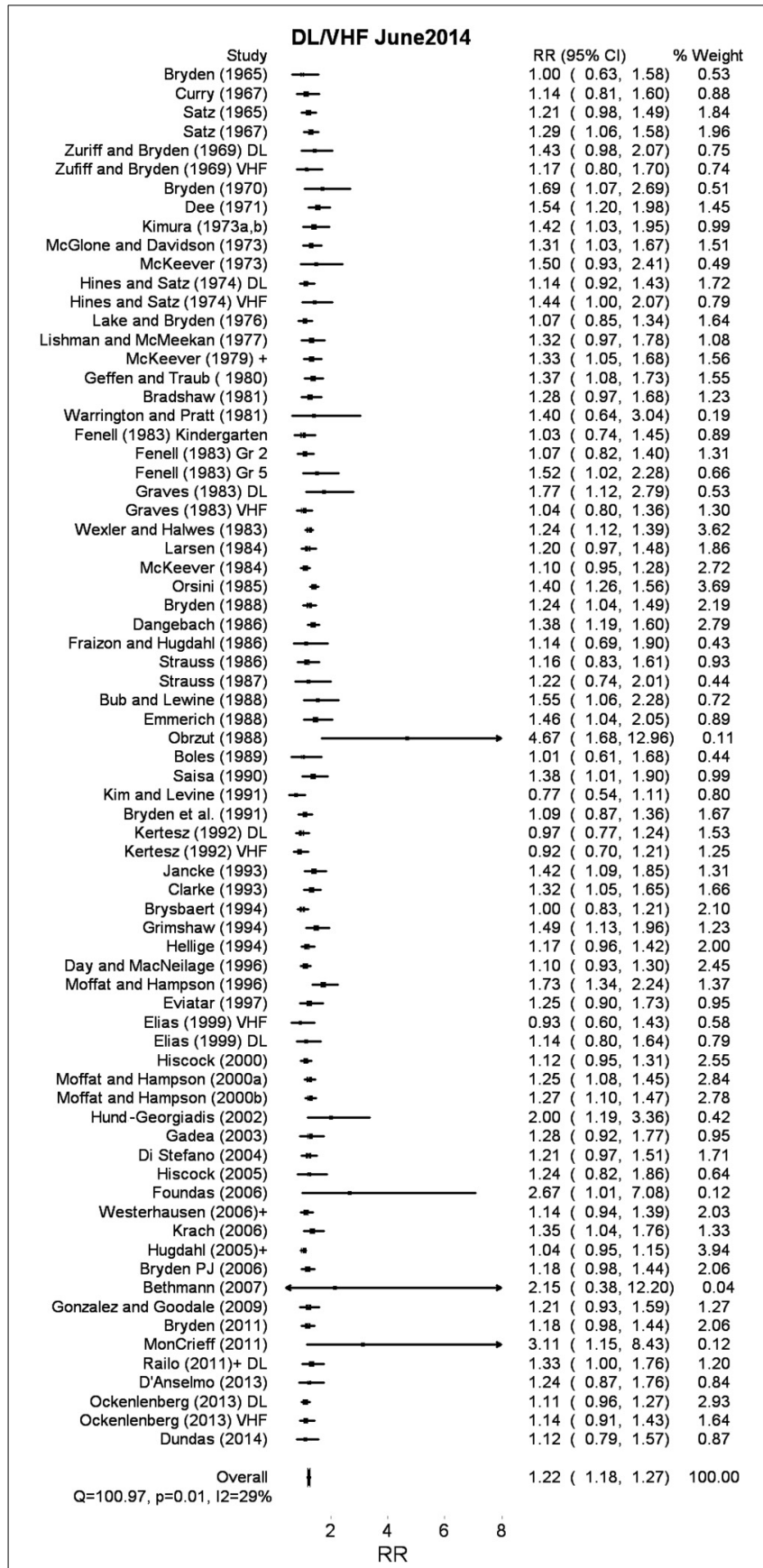

FIGURE 3 | Random effects meta analysis of right ear/right visual field bias for dextrals relative to adextrals.

temporal lobe epilepsy (TLE), compared to a control sample estimate of around 5\% (a three-fold increase); strong right handers were more common, but less dramatically so, in a right TLE group (84\%) compared to the strong right hander incidence in the control group (67\%). However, this sample was selected for medial temporal lobe epilepsy exclusively (and not for testing handedness incidence in epileptic people per se), as well as for relatively equal numbers of left TLE and right TLE patients (58 and 51, respectively). In another series, this time of 92 consecutive epileptic people with left hemisphere foci, 71 were right handed (79\%), and 20 were left handed or ambidextrous (21\%); the comparable numbers with right hemisphere foci were 55 right handers (77\%) and 16 adextrals (23\%; Stewart et al., 2014). These numbers can be compared to normal incidences in post-World War II Western societies of about $90 \%$ dextral, $10 \%$ adextal (McManus, 2002). Slezicki et al. (2009) find an increased incidence of adextrality of approximately 6\% in American and 3\% in Korean samples, totaling 478 people with epilepsy. Dellatolas et al. (1993) do find an increased incidence of left handedness in people with epilepsy, but only significantly so in individuals with brain damage so severe that they were hemiparetic. These data suggest that in some, but not all, series of epileptic patients, adextrality may be slightly more common that is usually detected in non-epileptic samples.

In fact, a little known consideration suggests that the dextrals in the original Montreal Neurological Institute cohort are not a completely random sample of all right-handed epilepsy patients. Reading the fine print of Rasmussen and Milner (1977) reveals that many dextral epileptic patients were not routinely given the WADA test prior to their surgeries; for example, those without adextral family members ${ }^{4}$. (Presumably left brain dominance was assumed in these dextral surgical candidates). Of course, if they weren't screened, they could not have contributed to the estimates in Table 1. Adextrals, as a matter of course, were tested regularly (also see Rey et al., 1988; Knake et al., 2003, for similar inclusion restrictions in other neurosurgical settings). One would think that the estimates for pre-selected dextrals could be "watered down" with respect to a "true" left hemispheric dominance measure, available only if all right handers were routinely administered the WADA. We think that this is unlikely, given near ceiling estimates of left dominance from most WADA studies (which is also consistent with much of the evidence in non-epileptics below), but keep the "pre-selection" issue in mind when reading critiques of WADA as a legitimate estimator of language lateralization in adextrals.

This issue of reorganization after early right or left hemisphere damage has been addressed to some extent by studies such as Stewart et al. (2014), Cunningham et al. (2008), Powell et al. (1987) and others, who identify speech dominance in patients with epileptic foci in the right hemisphere or the left. Eight of these studies are summarized in Table 2 (sadly, these include four experiments, of many, where only left temporal lobe epileptic patients were included). Samples with small n's (e.g., Staudt et al., 2002), no report of handedness or dextrals only (e.g., Helmstaedter, 1999; Brázdil et al., 2003; Raja Beharelle et al., 2010) or studies which have utilized pre-selection to include more people with anomalous dominance (e.g., Strauss and Wada, 1983) are omitted. Obviously studies that report the number of dextrals and adextrals in the sample, but do not provide separate language dominance for each group as a function of hemispheric locus,

\footnotetext{
${ }^{4}$ Familial sinistrality was once considered an extremely important moderator of cerebral asymmetries (e.g., Hécaen and Sauguet, 1971; reviewed by Bishop, 1980) but has largely fallen out of favor (e.g., Orsini et al., 1985; Bishop, 1990; although see Willems et al., 2014, which argues for its reinclusion as a moderator variable).
} 


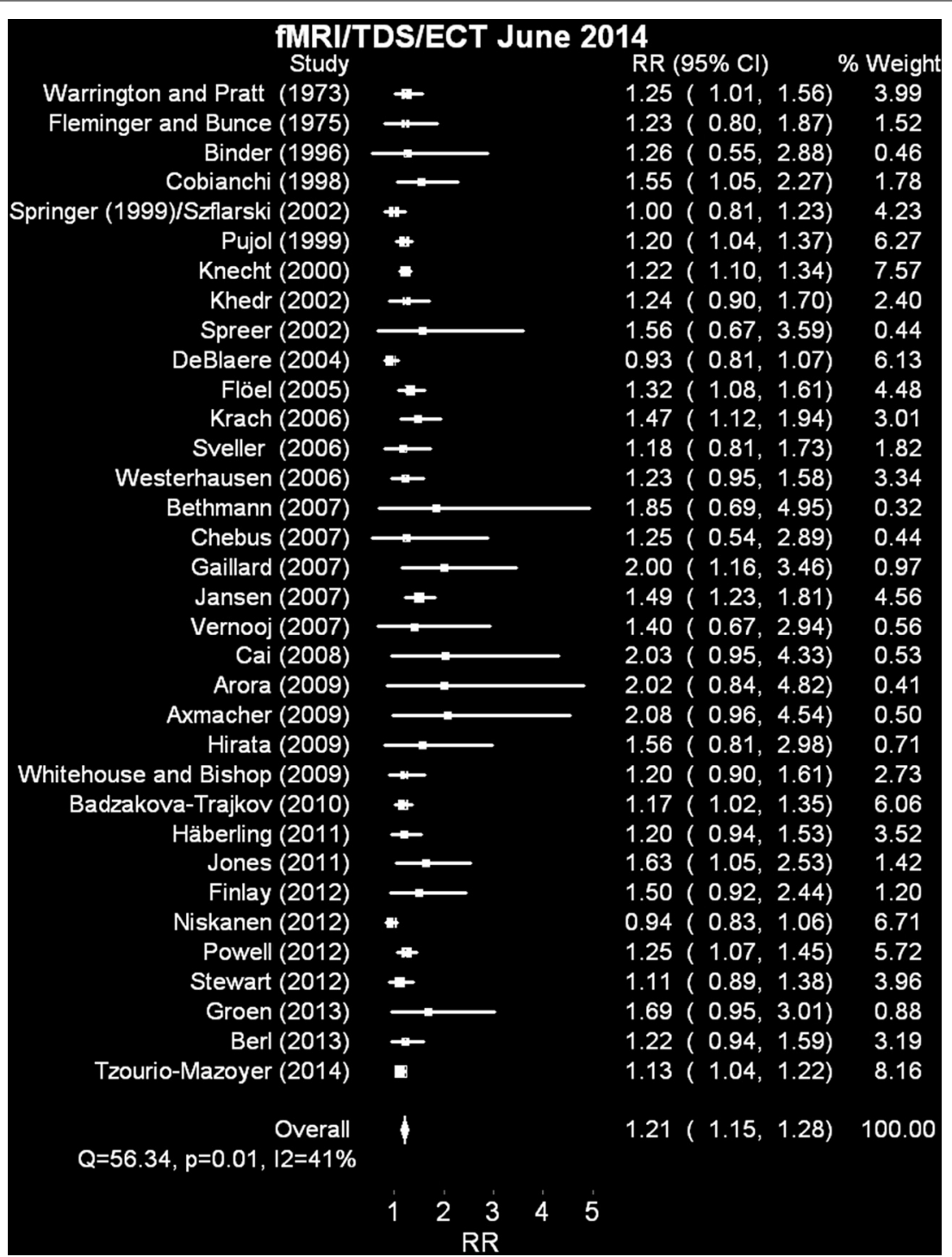

FIGURE 4 | Random effects meta analyses of fMRI + rate ratio of left brain dominance to anomalous dominance in dextrals relative to adextrals. The analysis including the excluded study (Basic et al., 2004) is available as Supplementary Material.

are also not included. A weighted means analysis does support the idea that left lesions (relative to right lesions) do drive up the incidence of anomalous dominance in the adextrals by over $26 \%$ (although note the tiny sample sizes) while in dextrals the increase is much smaller (about 11\%).

For expediency's sake, another crucial moderator of these effects has been ignored: whether or not the unilateral brain damage occurs early or late in life (the sample sizes in this domain, as usual in the adextrals in particular, do not inspire confidence in the parsimony of quantifying a four-way interaction between handedness group, language dominance, side of focus and age of injury).

In any case, anomalous dominance cannot be completely explained by left hemisphere damage in adextrals. Thirty years of functional and structural neuroimaging alone has put paid to any sort of "all left handedness (and/or anomalous dominance) follows from left hemisphere pathology," pushing a few unfortunate people away from a near $100 \%$ right-handed, lefthemisphere dominant phenotype. In fact, we often forget that $5-10 \%$ dextrals, by most estimates (see Table 2), may have anomalous dominance. Few would argue that these individuals have left hemisphere pathology. The pathological left hander account cannot be dealt with in any detail here. It, in any form, is complicated by the fact that genetic models have yet to account for any causal direction of language dominancehandedness relationships. In other words, any innate plan could be for handedness, which drives, incompletely, speech and language dominance, or, could be for speech and language dominance which drives, incompletely, handedness (see McManus, 1985, 2002; Yeo and Gangstead, 1993; Corballis, 1997; Annett, 2002; Klar, 2003; Armour et al., 2013; for further discussion). 
Table 2 | Speech dominance as a function of handedness and side of lesion/epileptic focus.

\begin{tabular}{|c|c|c|c|c|c|c|c|c|}
\hline & \multicolumn{4}{|c|}{ Left hemisphere lesions } & \multicolumn{4}{|c|}{ Right hemisphere lesions } \\
\hline & LD & AD & LD & AD & LD & AD & LD & $A D$ \\
\hline Cunningham et al., 2008 & $41 \%(7)$ & $59 \%(10)$ & $84 \%(53)$ & $16 \%(10)$ & $75 \%(9)$ & $25 \%(3)$ & $100 \%(55)$ & $0 \%(0)$ \\
\hline Gaillard et al., 2007 & $40 \%(8)$ & $60 \%(12)$ & $78 \%(64)$ & $18 \%(22)$ & - & - & - & - \\
\hline Helmstaedter, 1999 & $89 \%(16)$ & $11 \%(2)$ & $86 \%(4)$ & $14 \%(9)$ & $58 \%(7)$ & $42 \%(5)$ & $78 \%(58)$ & $22 \%(16)$ \\
\hline Powell et al., 1987 & $40 \%(2)$ & $60 \%(3)$ & $44 \%(4)$ & $56 \%(5)$ & $100 \%(3)$ & $0 \%(0)$ & $70 \%(7)$ & $30 \%(3)$ \\
\hline Stewart et al., 2014 & $55 \%(11)$ & $45 \%(9)$ & $85 \%(60)$ & $15 \%(11)$ & $94 \%(15)$ & $6 \%(1)$ & $93 \%(51)$ & $7 \%(4)$ \\
\hline Strauss et al., 1990 & $11 \%(1)$ & $89 \%(8)$ & $72 \%(13)$ & $28 \%(6)$ & - & - & - & - \\
\hline Strauss and Wada, 1983 & $25 \%(2)$ & $75 \%(6)$ & $94 \%(21)$ & $6 \%(4)$ & $100 \%(3)$ & $0 \%(0)$ & $100 \%(31)$ & $0 \%(0)$ \\
\hline Sveller et al., 2006 & $59 \%(13)$ & $41 \%(9)$ & $82 \%(50)$ & $18 \%(11)$ & - & - & - & - \\
\hline
\end{tabular}

Strauss et al. (1990) do not indicate if any patients overlap with Strauss and Wada (1983) so both are included. Weighted means were calculated as a function of the total number of adextrals or dextrals in the LD and AD columns, separately for left and right hemispheric lesions.

\section{META ANALYSIS 3: INDIRECT TECHNIQUES WITH NEUROLOGICALLY-INTACT PARTICIPANTS INTRODUCTION}

WADA testing of the sort described above became quite a common exercise in neurosurgery clinics from the 1970s onwards; in parallel, experimental psychologists were pursuing less direct methods for examining behavioral asymmetries that are related (in theory) to cerebral asymmetry for language. The two main methods, dichotic listening (where different sounds are presented to the two ears simultaneously) and tachistiscopic studies (visual half fields, presenting stimuli such as words or consonant-vowelconsonant syllables) can provide sensible estimates of cerebral asymmetries that are largely consistent with the aphasia and WADA test research. Unfortunately, the tendency to provide the proportions of any sample of dextral or adextral participants who show, for example right ear or left ear bias, fell out of favor relative to the usual null hypothesis significance tests, contrasting groups defined by handedness (and occasionally, sex, writing posture, familial presence of adextrality, and so on). Inevitably, these rather laborious large $\mathrm{n}$ studies began to fall out of favor, partly due to the fact that the results showed that dextrals were more lateralized than adextrals on any particular indirect measure (see Bryden, 1982 for a comprehensive review of the relevant literature from 1960s to the $1980 \mathrm{~s})^{5}$.

In other studies, particularly ones with smaller sample sizes, mean differences between dextrals and adextrals on any particular dependent measure were not statistically significant, leading authors to conclude that handedness has no effect (e.g., Goodglass and Barton, 1963; Hugdahl et al., 2012) or more recently, that any effects of handedness are small relative to larger

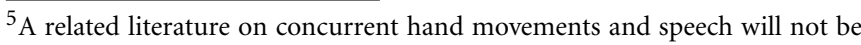
referred to here, as the vast majority of these papers only report measures of central tendency (e.g. Lomas and Kimura, 1976; Sussman, 1982; Murphy and Peters, 1994).
}

effects of more direct measures of language dominance (Van der Haegen et al., 2013b). Remarkably (to us, at least) Kimura herself, who helped launch dichotic listening as a valid paradigm in asymmetry research, had argued from some of her earliest data that dichotic listening scores do not discriminate between dextrals and adextrals (Kimura, 1961). Some years later, Bryden et al. (1983a), argued that hemispheric dominance accounts for about twice as much of the variance in dichotic listening as handedness does.

Nevertheless, these techniques might play some small role in identifying the probable language lateralization of individual people (if, for example, peripheral hearing differences between ears and attentional biases can be ruled out using forced attentional conditions, hearing tests and so on). They may also speak to estimates of the degree of left brain dominance in dextrals and adextrals if several weaker effects can be pooled using the techniques of meta analysis. Therefore, data on proportions of dextrals and adextrals who showed ear or visual field advantages were gleaned from the literature. Kim (1994) has previously performed an early meta analysis on VHF data; however his focus was on variance/central tendency in dextral and adextral groups rather than the proportions of participants in left right or bilateral language dominance categories.

\section{METHODS}

To be included in the current meta analysis studies must have provided frequencies of ear advantages (or visual field advantages) in dextrals and adextrals. These are, for historical reasons, more common in dichotic listening studies and much less common in divided visual field experiments (Hugdahl and Franzon, 1985). It may not be surprising to the reader by this point to learn that that many studies (sadly some with remarkably large samples) do not provide these data, and instead rely on inferential statistics on means and variances, test-retest correlations and the like (e.g., Orbach, 1967; Higenbottam, 1973; Briggs and Nebes, 1976; McKeever and VanDeventer, 1977; Hines et al., 1980; Geffen and Caudrey, 1981; Bryden et al., 1983b; Foundas et al., 2006). 


\section{RESULTS}

The 73 studies summarized included 6691 dextral and 3497 adextral participants. The results of this random effects meta analysis appear as Figure 3. Supplementary Material contains the raw data, and the meta analytic weights associated with each study. It also contains a number of studies not included in the analysis on a separate sheet. The obtained odds ratio of 1.22 (95\% CI 1.18-1.27) suggests that dextrals are more likely to show right ear/right visual field advantages relative to adextrals, in spite of considerable heterogeneity again $\left(Q=100.97, p=0.01 ; I^{2}=\right.$ $29.69 \%$ ). Of the 73 studies, all but 4 result in rate ratios greater than 1. It may be worth noting that the vast majority of these participants would have been taken from samples of university undergraduates (a population, especially in the selective days of the twentieth century university sector, who would be unlikely to be overly populated by adextrals with subtle left hemisphere pathologies). In Supplementary Material, we have also multiplied each proportion for dextrals and adextrals by the weights assigned by the meta analysis. For dextrals, the weighted mean is $83.2 \%$ left hemisphere biased; for adextrals the weighted mean is $68.2 \%$.

\section{DISCUSSION}

The direction of these data is consistent with the results of the WADA test analysis above, albeit with a slightly reduced pooled rate ratio in this case (1.22 vs. 1.37). It is difficult to unambiguously interpret this smaller rate ratio (in comparison with the WADA rate ratio reported above) as an effect of reduced sensitivity of indirect tests like DL and VHF experiments. Theoretically, measures that are more indirect would result in higher proportions of participants being assigned to the anomalous dominance category, but we can see no obvious reason why such a bias would interact in some meaningful way with handedness group. The final paradigm-driven meta analysis below may speak to this difference to some extent.

\section{META ANALYSIS 4: FUNCTIONAL MAGNETIC RESONANCE IMAGING (fMRI), ELECTRO-CONVULSIVE THERAPY (ECT) AND TRANSCRANIAL DOPPLER SONOGRAPHY (TDS) INTRODUCTION}

Other techniques were brought to bear in the 1970s which speak to language lateralization in dextrals and adextrals beyond the indirect perceptual techniques summarized above in Meta Analysis 4. For example, Elizabeth Warrington and Richard Pratt realized that inferences similar to those made using the WADA test could be made by studying speech arrest in patients undergoing electroconvulsive therapy (ECT) for psychiatric disturbances such as depression. In a sample of 55 right handed patients, speech dysfunction was elicited after left skull ECT in 100\% of them (Pratt and Warrington, 1972). In a later study, Warrington and Pratt (1973) extended the method to 24 left handers and found left sided speech arrest in $70 \%$ of the sample. A later independent study by Geffen et al. (1978) reported 80\% left hemispheric dominance in a sample of 31 right handed patients a few years later.

We have grouped ECT, used in this way, with the more modern methods described below as the similarity to transcranial magnetic stimulation (TMS) is a striking one. Of course, by the 1990s, additional technologies have been brought to bear on questions related to language laterality and handedness. Unfortunately (for our purposes here) many of the samples have largely been devoted to documenting the usefulness of $\mathrm{AMRI}$ as a replacement for the WADA test (see Medina et al., 2007; Bauer et al., 2014 for reviews of this extensive literature), typically in smaller samples of patients about to undergo epilepsy surgery. We use the term smaller here regarding our purposes of course, which in an ideal world would include many dextrals and adextrals reported on as separate groups. Understandably, these small samples tend to contain very few (if any) adextral participants (Desmond et al., 1995; Binder et al., 1996; Worthington et al., 1997). A similar problem exists for several papers which have attempted to use repetitive TMS for the same purpose (Abou-Khalil, 2007, reviews several of these papers). The exception to this rule is included (Khedr et al., 2002).

Nevertheless, a handful of $\mathrm{AMRI}$-WADA comparison experiments (and a small number of papers using other methods, such as TDS and magnetoencephalography-MEG) have collected either so many participants over time that a number of adextrals are included, or, rarely, have by design pursued additional adextrals (usually to increase likely variance in speech dominance). Thirty-five such studies, as well as large $\mathrm{n}$ fMRI studies in non-epileptics which include adextrals, are summarized in Table $3^{67}$. Note that many of these experiments will be based on epileptic participants, so will be subject to the same caveats mentioned above regarding WADA study results.

A major concern, well understood by neuroimagers in this field, is the continuous nature of activation data revealed in individuals performing language-relevant tasks in the scanner. For our purposes here, we will ignore methodological differences (particularly those related to decisions regarding defining bilateral speech representation from continuous fMRI data-see Binder et al., 1996; Baciu et al., 2005; Bethmann et al., 2007; Vigneau et al., 2011; for some of the debates regarding precise procedures).

We also include studies in this analysis which use other measurement techniques based on blood flow, such as transcranial Doppler sonography (TDS). The grouping together of such diverse methods (ECT, fMRI, MEG, EEG, and TDS) may alarm researchers who use such techniques regularly. Nevertheless, in our mind they are less comfortably grouped with the aphasia literature, or with the indirect perceptual tasks such as DL or VHF experiments.

It is not surprising that the vast majority of studies examining the cerebral organization of language with these newer paradigms test right handers exclusively (e.g., Neville et al., 1998; Parker et al., 2005; Pillai and Zaca, 2011). On the other hand, some fMRI/EEG/TDS researchers may be biased by the overlap between

\footnotetext{
${ }^{6}$ Several studies which focussed on dextrals exclusively will not be summarized here. Representative papers that result in cerebral asymmetry classifications largely consistent with the dextral means from fMRI, WADA, ECT and TDS include (Kompus et al., 2012; Ocklenburg et al., 2013).

${ }^{7}$ We are also excluding studies where inclusion criteria influenced the likelihood of increased incidence of anomalous dominance (e.g., Sabbah et al., 2003), with the exception of the pursuit of adextrals of course.
} 
Table 3 | fMRI/ECT/TDS studies of language lateralization.

\begin{tabular}{|c|c|c|c|c|c|c|c|}
\hline Study & Dextral n & LD (\%) & AD (\%) & Adextral n & LD (\%) & RD (\%) & LD diff (Dex-Adex) \\
\hline Arora et al., 2009 & 30 & 87 & 13 & 10 & 20 & 75 & +67 \\
\hline Axmacher et al., 2009 & 24 & 83 & 17 & 10 & 40 & 60 & +43 \\
\hline Badzakova-Trajkov et al., 2010 & 107 & 95 & 5 & 48 & 81 & 19 & +14 \\
\hline Benson et al., 1999 & 11 & 100 & 0 & 8 & 75 & 25 & +25 \\
\hline Berl et al., 2013 & 185 & 75 & 25 & 39 & 62 & 38 & +13 \\
\hline Bethmann et al., 2007 & 26 & 92 & 8 & 5 & 50 & 50 & +42 \\
\hline Binder et al., 1996 & 19 & 84 & 16 & 3 & 67 & 33 & +17 \\
\hline Cai et al., 2008 & 10 & 90 & 10 & 9 & 44 & 56 & +46 \\
\hline Chlebus et al., 2007 & 12 & 83 & 17 & 3 & 67 & 33 & +16 \\
\hline Cobianchi and Giaquinto, 1998 & 18 & 94 & 06 & 18 & 61 & 39 & +33 \\
\hline Deblaere et al., 2004 & 14 & 93 & 07 & 4 & 100 & 0 & -7 \\
\hline Findlay et al., 2012 & 21 & 86 & 14 & 14 & 57 & 43 & +29 \\
\hline Fleminger and Bunce, 1975 & 44 & 82 & 18 & 8 & 67 & 33 & +15 \\
\hline Flöel et al., 2005 & 37 & 97 & 03 & 38 & 74 & 26 & +23 \\
\hline Gaillard et al., 2007 & 80 & 80 & 20 & 20 & 40 & 60 & +40 \\
\hline Groen et al., 2013 & 45 & 84 & 16 & 12 & 50 & 50 & +34 \\
\hline Häberling et al., 2011 & 35 & 91 & 9 & 25 & 76 & 24 & +15 \\
\hline Hirata et al., 2010 & 54 & 89 & 11 & 7 & 57 & 43 & +32 \\
\hline Jansen et al., 2007 & 130 & 98 & 02 & 53 & 66 & 34 & +22 \\
\hline Jones et al., 2011 & 47 & 92 & 02 & 16 & 56 & 36 & +26 \\
\hline Khedr et al., 2002 & 25 & 84 & 16 & 25 & 68 & 32 & +16 \\
\hline Knecht et al., 2000 & 155 & 95 & 05 & 132 & 78 & 22 & +17 \\
\hline Krach et al., 2006 & 29 & 97 & 03 & 29 & 66 & 34 & +31 \\
\hline Loring et al., 1990 & 91 & 80 & 20 & 12 & 75 & 25 & +5 \\
\hline Mazoyer (sub) & 144 & 94 & 06 & 153 & 84 & 16 & +10 \\
\hline Niskanen et al., 2012 & 16 & 94 & 06 & 4 & 100 & 0 & -6 \\
\hline Powell et al., 2012 & 42 & 100 & 0 & 40 & 80 & 20 & +20 \\
\hline Pujol et al., 1999 & 50 & 98 & 02 & 50 & 82 & 18 & +16 \\
\hline Spreer et al., 2002 & 18 & 78 & 22 & 5 & 40 & 60 & +38 \\
\hline Springer et al., 1999/Szaflarski et al., 2002 & 50 & 78 & 22 & 50 & 78 & 22 & 0 \\
\hline Stewart et al., 2014 & 126 & 88 & 12 & 36 & 72 & 28 & +16 \\
\hline Sveller et al., 2006 & 61 & 82 & 18 & 13 & 69 & 31 & +13 \\
\hline Tzourio-Mazoyer et al., 2014 & 144 & 94 & 06 & 153 & 84 & 16 & +10 \\
\hline Van der Kallen et al., 1998 & 14 & 100 & 0 & 6 & 17 & 83 & +83 \\
\hline Vernooij et al., 2007 & 10 & 70 & 30 & 10 & 50 & 50 & +20 \\
\hline Warrington and Pratt, 1973 & 52 & 98 & 02 & 23 & 78 & 22 & +20 \\
\hline Westerhausen et al., 2006 & 42 & 81 & 19 & 47 & 66 & 34 & +15 \\
\hline Whitehouse and Bishop, 2009 & 45 & 80 & 20 & 30 & 67 & 33 & +13 \\
\hline Weighted mean & & $91 \%$ & $9 \%$ & & $76 \%$ & $24 \%$ & \\
\hline
\end{tabular}

Classification techniques vary somewhat, as do criteria for bilateral language classification (hence my grouping of bilateral and right dominance classifications as anomalous dominance). The final column represents the difference between dextrals and adextrals in the percentage of that sample which is left hemisphere dominant. The weights in the associated meta analysis were used to calculated the weighted percentages at the bottom of the table. The difference between the two weighted LD means is equivalent to a risk ratio, dextrals to adextrals, of 1.17.

dextrals and adextrals to the point that handedness is no longer even mentioned in the methods sections of individual papers (e.g., Wang et al., 2012; Bellugi et al., in press). This state of affairs is no doubt exacerbated by the rarity of adextrals in any small or medium sized sample of individuals, patient groups or otherwise.

Other fMRI experiments have contrasted reasonably large samples of dextral and adextral participants on various language, memory and spatial tasks, but the emphasis in analysis is on measures of central tendency from the entire group (e.g., Gur et al., 1982; Cuzzocreo et al., 2009) or they only report main effects or other data that do not allow for the risk ratio calculations used here (e.g., Miller et al., 2005). Structural investigations using techniques such as diffusion tensor imaging (DTI) are now appearing which include dextrals and adextrals as separate groups, but they often do not have functional data on their participants or, as is often the case, focus on measures of central tendency at the group level (Hagmann et al., 2006). 


\section{METHODS}

Many of the papers included in this analysis were identified by related reference and cited reference searches for classic papers such as Rasmussen and Milner (1977). Literature searches for this set of studies on fMRI and handedness, TDS and handedness, ERP and handedness, included many papers that we then excluded for reasons above. We also identified papers which cite some of the original large $\mathrm{n}$ fMRI handedness studies including Benson et al. (1999), Knecht et al. (2000; a large n TDS paper), Pujol et al. (1999), Springer et al. (1999), etc. This final paradigmbased random effects meta analysis uses the data of Table 3 to create rate ratios for left dominance, dextrals relative to adextrals.

\section{RESULTS}

The 35 studies summarized included 1870 dextral and 1066 adextral participants. The results of this analysis appear in Figure 4. One unusual TDS paper (Basic et al., 2004) found 92\% right brain dominance in their adextral group, a highly unusual result (equal to an odds ratio of 11.67 for this particular study, compared to a range of 1.00-2.08 for the other 34 experiments). Therefore, it was dropped from the analysis (Supplementary Material includes it for comparison purposes). The revised overall risk ratio for left hemispheric dominance in dextrals compared to adextrals is 1.21 (95\% CI 1.15-1.28; $Q=56.34, p=0.01, I^{2}=41 \%$ ). We also modeled \% left dominance in these studies by weighting each group percentage by the meta-analytically derived inverse weighting. This procedure suggests a best estimate, on average, of left brain dominance in dextrals of $90 \%$ and in adextrals, $73 \%$ (data available on sheet 1 in Supplementary Material).

\section{DISCUSSION}

This overall effect estimate is remarkably similar to the one associated with Figure 3 based on the dichotic listening/visual half field results (overlap between these two meta analyses is less of an issue than overlap between the fMRI/ECT/TDS and WADA test analyses, discussed below in Experiment 6, although three studies do overlap with other paradigm specific meta analyses above).

\section{A META META ANALYSIS? INTRODUCTION}

Recently, advocates of meta analytic techniques have pondered how subgroups can be compared statistically (Schmidt and Hunter, 2015). For example, the rate ratios for the different domains described here can be compared with one another, and the effects on heterogeneity can be modeled by including them all in an omnibus meta analysis. Adding or subtracting different subgroups (in a fashion not unlike hierarchical regression) could reveal informally the relative contributions to heterogeneity. One of the reviewers of a previous version of this manuscript suggested that all of the studies could be included in an omnibus meta analysis, with the degree of heterogeneity across the subgroups established.

According to the Cochrane collaboration (Deeks et al., 2011), such comparisons have to be made with caution. Differences in the magnitude of effects or degree of heterogeneity cannot be unambiguously related to subgroup membership exclusively. For example, in the particular case here, random effects meta analysis will re-weight all of the studies based on the inverse of their variance. This re-weighting means that within experiment sample sizes as well as the number of different experiments identified by the literature search will affect how different studies contribute. Nevertheless, we have performed an overall rate ratio meta analysis using all of the DL/VHF, WADA, and fMRI/ECT/TDS studies.

\section{METHODS}

An inverse variance random effects model instantiated in RevMan) 5.0 (2008), provided by the Cochrane Collaboration (http://www.cochrane.org/) was used for the omnibus analysis. It can be downloaded freely here: http://tech.cochrane.org/ Revman. The graphical capabilities of this software are rather limited, so we have continued to use MetaXL for the main studies reported above. We used RefMan for this final analysis as it provides decent summary statistics about subgroups in a way that MetaXL does not. Identical rate ratios and confidence intervals are provided by both packages for DL/VHF, WADA tests, and fMRI/ECT/TDS analyses. The Cochrane Handbook recommends random effects for subgroup analysis: "Tests for subgroup differences based on random-effects models may be regarded as preferable to those based on fixed-effect models, due to the high risk of false-positive results when comparing subgroups in a fixedeffect model (Higgins and Thompson, 2004)" (Deeks et al., 2011; 9.6.3.1).

\section{RESULTS}

Supplementary Material provides the graphical summary, rate ratios and heterogeneity estimates for the entire analysis as well as the subgroups. Note that the weights applied to each individual study change relative to those computed when each subgroup was subjected to its own meta analysis (Figures 2-4). In fact, the sheer number of DL/VHF tests, along with their relatively large numbers of dextral and adextral participants, means that they account for $59.3 \%$ of the overall analysis (WADA $=16.5 \%$ and $\mathrm{fMRI} / \mathrm{ECT} / \mathrm{TDS}=24.1 \%)$. Unsurprisingly, the overall rate ratio estimate is quite similar to those for the DL/VHF and the fMRI/ECT/TDS analyses: 1.25 (95\% CI = $1.22,1.29$ ).

RevMan uses the significance test for subgroup differences recommended by Borenstein et al. (2008). Essentially it tests for heterogeneity across subgroups rather than across individual studies. It also provides an $\mathrm{I}^{2}$ estimate describing variability due to subgroup differences that is not accounted for by sampling error. We have violated the assumption that the datasets are truly independent, as some participants from WADA tests were also scanned in parallel fMRI/MEG experiments (e.g., Spreer et al., 2002; Axmacher et al., 2009; Hirata et al., 2010). In this instance, the subgroup value of $\mathrm{Chi}^{2}(2)=6.69, p<0.05 . I^{2}=$ $70.1 \%$, suggesting significant variability across subgroups. This significant heterogeneity may be largely due to the WADA test subgroup, as an additional "semi" omnibus test including only the $35 \mathrm{fMRI} / \mathrm{ECT} / \mathrm{TDS}$ experiments and the $72 \mathrm{DL} / \mathrm{VHF}$ experiments reveals no significant heterogeneity $\left(\mathrm{Chi}^{2}(1)=0.07, p>\right.$ $0.05)$ and a significant rate ratio $(Z=13.67, p<0.0001)$ of 1.22 $(95 \%$ C.I. $=1.19,1.26)$. 


\section{DISCUSSION}

As noted above, comparing these subgroups has to be done with caution, as there are considerable differences in study number, within study sample size and some non-orthogonality, as some individuals appear in more than one paradigm. Nevertheless, this final analysis does suggest heterogeneity across methods, at least when comparing the WADA test analyses to the others. The analysis supports what the individual meta analyses above suggestlittle difference in rate ratios across DL/VHF experiments and the (mainly) more recent studies using fMRI/ECT/TDS methods. There is little overlap of participants between these two sets of experiments. These data are somewhat surprising, given the indirect nature of these behavioral tests and how they may be confounded with attentional and perceptual factors. (Such caveats are rarely made about the results from the newer methods such as fMRI.)

\section{GENERAL DISCUSSION}

All of the analyses, bar one, show increased left brain dominance for language in the dextrals of approximately $20 \%$. The least conclusive analysis, in terms of the absolute difference between dextrals and adextrals was for aphasia incidence after left brain damage. Although an effort was made to exclude patient series where some pre-selection was made or implied, it is difficult to evaluate the success of such an enterprise. For example, most of those studies were published pre-1980, which means that, for obvious reasons, additional information about how the experiments were conducted is no longer possible to come by. The most recent, Kimura (1983), for example, parallels her arguments from the 1960s for no difference between dextrals and adextral samples on dichotic listening: she found no differences between her adextrals and dextrals in aphasia incidence after right brain damage (3 vs. $2 \%$, respectively). This sample did show, however, that left brain damage was less likely to lead to aphasia in the adextrals $(23 \%$ to the dextral $41 \%)$. This pattern of data is slightly counterintuitive to our first two meta-analyses, which suggest that aphasia after right brain damage separates dextrals and adextrals more effectively.

Is Kimura's sample unusual in some respect? The number of adextrals reported was amongst the better in this kind of study (37 with left brain damage, 30 with right brain damage). She claims that $9 \%$ of the sample of patients with unilateral brain damage were adextral (a sensible estimate given what is known about handedness); although her definition of adextrality was quite inclusive (if $<7 / 8$ items on her handedness questionnaire indicated the right hand). This kind of in depth analysis of individual papers is dangerous in this context, of course, as scientists tend to be overly analytic of results that are counterintuitive (see below).

The evidence for dysphasia incidence after right brain damage is clearer. The susceptibility of adextrals to dysphasia is over six times higher relative to the dextral samples. In spite of this clear difference, there still remains some uncertainty about whether or not all dextrals and adextrals would have been tested routinely for aphasia after right brain damage. Sadly, these sorts of studies have largely gone out of fashion, in spite of the fact that stroke registers, computerized databases and so forth should mean that these kinds of data could be collated after the fact, in many centers, at a time where much more information about etiology, lesion size and location, could be recorded routinely as part of the electronic record. Handwriting hand, in a pinch, would suffice, if sample sizes were sufficiently large (many handedness researchers may have concerns about such a recommendation). Almost all of the relevant information (in the later twentieth century) related to atypical dominance, lesion location and so on has come from the single case literature on crossed aphasias, apraxias and hemispatial neglect. We argue that the limitations of WADA testing of people with epilepsy are circumvented with the study of patients with acute brain damage.

Aphasia data aside, the other meta analyses differ slightly in terms of the precise rate ratios obtained. The rate ratio from WADA testing (1.36) is somewhat higher than that obtained from the DL/VHF and fMRI/ECT/TDS analyses (1.22 and 1.26, respectively). As Table 2 shows, language dominance is driven away from the hemisphere of epileptic focus to some extent in both dextral and adextral patients. These issues are discussed in great detail in several analyses (Helmstaedter et al., 1997; Springer et al., 1999; Dijkstra and Ferrier, 2013; Stewart et al., 2014).

In spite of the larger rate ratio obtained from the WADA experiments, the similarity in rate ratios obtained from DL/VHF and $\mathrm{fMRI} / \mathrm{ECT} / \mathrm{TDS}$ is encouraging. Heterogeneity is clearly an issue within both domains $\left(I^{2}=28.7 \%\right.$ for DL/VHF, $62.4 \%$ for fMRI/ECT/TDS), but our original suggestion that an inclusive meta analytic approach could cope with some of this heterogeneity is supported by the consistent rate ratios. The convergence from these different domains is noteworthy, given that many neuroimagers are struck by bilateral activations in any languagerelated task. Cerebral specialization has received less attention in the last 20 years than expected, given its huge importance in the earliest type of "cognitive neuroscience"-neuropsychology.

A rate ratio cannot be used to predict the percentage of dextrals or adextrals who are likely to be left hemisphere dominant for speech. One could use the ratio to predict that value in one group, if the other mean percentage is known or hypothesized. Instead of that kind of calculation, we used the inverse variance weights assigned to each experiment to estimate weighted dominance percentages. The results are interesting, but may need more careful modeling. For DL/VHF, the weighted estimate is $83 \%$ left brain dominance in the dextrals; $68 \%$ left brain dominance in the adextrals (a 15\% difference in the expected direction). For WADA our estimates suggest $87 \%$ left dominance in the dextrals and $65 \%$ left dominance in the adextrals a $22 \%$ difference). Finally, for $\mathrm{fMRI} / \mathrm{ECT} / \mathrm{TDS}$, the numbers are $88 \%$ left dominance in the dextrals and 64\% left dominance in the adextrals (a 24\% difference). Are there any good theoretical or empirical reasons to place more stock in one of these estimates more than the others?

These estimates, for the dextrals in particular, are slightly lower than the $90 \%+$ predicted by many of the early group studies (e.g., Rasmussen and Milner, 1977). In addition, genetic models such as McManus' DC theory (McManus, 1985) and Annett's Right Shift theory (2000) make similar $>90 \%$ left dominance predictions for dextrals. Of course any estimates will depend to some extent on how liberal or conservative the criterion is for inclusion in a left brain dominant or no dominance group (grouped with right 
brain dominance for our purposes here). For meta analyses and the associated rate ratios, what mattered was that within-study the same criterion was applied to dextral and adextral groups. These estimates for left brain dominance would change with criteria: for example in the work of Brysbaert, Van Der Hagen and their colleagues, a conservative criterion was adopted to ensure strong hemispheric asymmetry in a number of identified individuals. That criteria results in estimates of no atypical dominance in dextrals and about 10\% in adextrals (Brysbaert et al., 2012; Van der Haegen et al., 2013a,b) well below the estimates derived in the present analysis. It may be that our estimates of left brain dominance of $85 \%$ in dextrals may be somewhat conservative, by assigning more weak "left hemispheric" scores on tasks such as dichotic listening to a no dominance grouping.

Each of these research domains has its own associated weaknesses and strengths for helping to determine the underlying distributions of cerebral asymmetry. WADA testing, as noted above and elsewhere, is limited methodologically for several reasons (what counts as speech arrest, test-retest reliability, etc.), but the most concerning limitation is that congenital brain damage may bias dominance in some unknown (and unknowable) proportion of the patients (see Table 2). A strength of WADA, however, is the relatively unambiguous trichotomous data that it provides.

These estimates are in stark contrast to those from neuroimaging, where several methodological issues make simple left, right, bilateral classifications more contentious. For example, calculating a laterality index from functional data requires some hard decisions about regions of interest and thresholding (e.g., Jansen et al., 2006; Abbott et al., 2010), equating regions from each hemisphere which are not structurally identical (Shapleske et al., 1999), and the nature of baseline conditions (Seghier, 2008). Practical issues for imaging include expense (these asymmetry studies benefit from large sample sizes) and the difficulties inherent with interpreting data from single participants (Bosch, 2000; Fedorenko et al., 2010).

Sample size and expense are not particularly crucial issues for DL/VHF studies with neurotypical university undergraduates. These methods, as discussed above, are the most indirect measures of brain asymmetry, have relatively poor test-retest reliabilities and estimates in single participants can be seriously distorted/biased by attentional strategies, task demand and the like.

A reviewer of a previous draft suggested rating studies for their quality (i.e., presence of absence of the different cofounding effects mentioned above, for example) in order to evaluate the sources of heterogeneity more carefully. This suggestion is indeed tempting, as several of the estimates in each domain strike us as improbable, but were included nevertheless (with one exception in the fMRI/ECT/TDS paradigm analysis). In fact, after generating each forest plot it is extremely tempting to discard the wilder appearing estimates which appear outside the range of the other studies. In the ideal world of "new statistics," file drawer problems and biases against null effects and the like would be minimal, as ideally all datasets would be available electronically for meta analytic use (Cumming, 2012, 2013). We do not as of yet operate in such a world. Impressions about quality inevitably will reflect some of the personal biases about what the "true" differences between dextral and adextrals are. Another difficulty with a quality approach is that for many of the possible sources of noise discussed above and in detail elsewhere, their presence, absence or magnitude is hard to quantify. In some cases (as suggested by Kimura, 1983 regarding the aphasia incidence literature), there are reasons to suspect whether or not samples are truly random, or that all dextrals and adextrals were tested and none were preselected in any fashion whatsoever. In a few instances, the samples were not selected for writing hand alone. We have largely ignored historical covariates like familial sinistrality, foot preference or sex, as these tended to apply to both dextral and adextral samples in a similar fashion (in so far as we could tell). Nevertheless, it's likely they would muddy the waters somewhat, if the focus was restricted to a small number of key experiments.

\section{THEORETICAL SIGNIFICANCE OF PROPORTIONS OF DEXTRAL AND ADEXTRAL LANGUAGE DOMINANCE}

Excessive concern over precise estimates of cerebral dominance in adextrals, relative to dextrals, might seem a rather specialist sort of worry. Obviously, if the proportion of left hemisphere dominance in adextrals is much higher than these meta analyses suggest, then adextrals and dextrals may not differ in this aspect. Such a result would remove at least one of the major sources of neuropsychological interest in handedness. On the other hand, if adextrals (or very strong left handers at least; see Knecht et al., 2000) were largely right hemisphere dominant for speech, the so-called "Broca's rule" would actually apply, therefore much of the mystery surrounding left handers would largely disappear (i.e., handedness and cerebral dominance for speech and language would predict one another in some direct fashion). The present data, in spite of some of the limitations discussed above, suggest a more complex relationship between handedness and cerebral specialization than either of those two extremes. Practically speaking, a more precise estimate of the degree of language dominance, in both dextrals and adextrals, does have important ramifications, in at least three ways.

First, identifying the more appropriate "phenotype" for many studies (behavioral, genetic, neuroimaging, EEG etc.) could be aided considerably by knowing how many (and which) adextrals have crossed or uncrossed control of speech and limb function. For example, studies of asymmetries that tend to favor the right hemisphere in dextrals, such as face processing (Kanwisher, 1997; Yovel et al., 2008; Meng et al., 2012) and in particular, functions related to paralinguistic aspects of speech such as prosody (van Rijn et al., 2005; Ross and Monnot, 2008) would benefit greatly from knowing which individuals are largely left or right hemisphere dominant for typical speech and language function. In fact, an older literature on "complementary hemispheric specialization" (Bryden et al., 1983a; Elias et al., 1999a,b) has been largely forgotten about, but is ripe for a revival (Cai et al., 2013).

Similarly, organization of subregions of left hemisphere networks in individual or groups of dextrals (Fedorenko et al., 2012a,b) could be contrasted with their counterparts in right dominant individuals, if they could be identified at the individual or small group level. Additionally studies of increased incidence of adextrality in conditions such as dyslexia, autism, developmental coordination disorder and language-specific impairment might 
be more conclusive if cerebral control of hand and speech were the independent variables, rather than handedness (typically restricted to writing hand).

Second, more precise estimates of language dominance proportions could open up new studies of manual behaviors, particularly ones which are not hand-writing. It may be that one of more of these other manual behaviors (e.g., reaching and grasping, for example; Gonzalez et al., 2007; Gonzalez and Goodale, 2009) or gesturing (Kimura, 1973a,b) might be right hand biased in a significant proportion of "left" handers (as defined by writing hand). In other words an ideal predictor of cerebral dominance for language would be right hand biased in approximately $85 \%$ of a sample of dextrals, and $65 \%$ of a sample of adextrals. Sadly, almost all studies which contrast dextrals and adextrals on measures of hand choice, hand preference patterns, indirect measures of asymmetry such as DL and VHF studies, and so on inevitably report measures of group tendency and variability and fail to say anything about subgroups (of particular relevance in the adextral samples if sufficiently large and well characterized). Our suspicion is that these possible predictor behaviors need to be measured in the lab or the real world, rather than reported on via a paper and pencil questionnaire (Carey et al., 2009; Gonzalez and Goodale, 2009).

For example, the relatively poor correlations between VHF and DL experiments, or test-rest correlations with the same measures might benefit from a more considered analysis of proportions of the samples who show effects in one direction or the other. A test might have poor reliability because its precise estimate is noisy, yet it might classify individuals dichotomously quite well. It seems probable that people with larger scores on these indirect tests might be less likely to show significant changes on retest (at least in direction), in which case participant performance could be examined more carefully in the individuals who score nearer to zero (are they following task instructions, are they in fact less lateralized across many measures etc.). This kind of approach presupposes a more considered analysis of an individual's performance on two versions of the same test or across different indirect tests.

A third reason why precise estimates of language dominance are of interest is related to sensorimotor control and handedness. In the vast majority of dextrals, the hemisphere more specialized for speech and language is largely in control of the dominant hand, at least at the levels of motor/premotor output and somatosensory input. From a handedness perspective, clearly something very different is going on in the majority of adextrals. In this context, (related to, but not synonymous with, motor theories of speech perception; e.g., Lieberman, 2006; MacNeilage, 2008), there should be subtle benefits ("privileged access") in sensorimotor control for having the dominant hand intimately interconnected with the motor, premotor and somatosensory cortices of the same hemisphere that largely controls the speech musculature (Goodale, 1988; Carey and Otto-de Haart, 2001). A corollary of this idea is that, for the majority of adextrals, the non-dominant hand might enjoy benefits for the same reason, at least when compared to the non-dominant hand of dextrals, which statistically, is likely to have privileged access to attentional and visuospatial networks (Mieschke et al., 2001; Carey and Liddle, 2013). Surprisingly, very few studies compare absolute levels of performance in these "four hands" (the few that do are typically a little underpowered when it comes to the size of the adextral sample; e.g., Goodale, 1990; Boulinguez et al., 2001).

In conclusion, efforts to establish precise estimates for dextral and adextral language asymmetry are challenged by pre-selection biases, poor sample sizes, and incomplete reporting of data. The tendency for adextrals to be left hemisphere dominant is conceived (by different scientists) to be an unwanted source of heterogeneity (they therefore just test dextrals). Another approach is to ignore adextrals altogether (e.g., don't record handedness at all, or at least don't report it), as they are relatively rare folk who, for the most part, are arranged as the right handed majority anyway. Nevertheless, these meta analyses reinforce the idea that adextrals have an unusual cerebral arrangement vis-à-vis the control of speech and language vs. control of their dominant hand.

\section{ACKNOWLEDGMENTS}

Alan Beaton and two other (anonymous to us at the time) referees provided helpful comments on earlier drafts of this manuscript. Leah T. Johnstone is supported by a Bangor University 125 Anniversary Research Scholarship. Patricia Bestelmeyer, Guillaume Thierry, and Mihela Erjavec provided translation of non-English papers and theses. Lauren Harris helped us navigate some of the rather complex arguments regarding pathological left handedness. Several scientists answered questions or provided additional supplementary information which allowed for inclusion or exclusion in some of the meta analyses reported herein: Abul Alzahrani, Elena Azanon, Anna Basso, Ursula Bellugi, Madison Berl, Pamela Bryden, Marc Brysbaert, David M. Corey, Anita D’Anselmo, Lainy Day, Dale Dagenbach, Eva Dundas, William Gaillard, Elizabeth Hampson, Markus Hausmann, Marco Hirnstein, Kenneth Hugdahl, Julie K. Janecek, Blake Johnson, Kristina Kompus, Peter MacNeilage, Zachary Miller, Scott Moffat, Deborah Moncrieff, Sebastian Ocklenburg, Godfrey Olivier, Rene Westerhausen, Stephanie Lehericy, Kelly Murphy, Sid Segalowitz, Christopher C. Stewart, Lionel Thivard, Lise Van der Haegen, Ark Verma, Daniel Voyer, and Bernd Weber.

\section{SUPPLEMENTARY MATERIAL}

The Supplementary Material for this article can be found online at: http://www.frontiersin.org/journal/10.3389/fpsyg. 2014.01128/abstract

\section{REFERENCES}

Abbott, D. F., Waites, A. B., Lillywhite, L. M., and Jackson, G. D. (2010). fMRI assessment of language lateralization: an objective approach. Neuroimage 50, 1446-1455. doi: 10.1016/j.neuroimage.2010.01.059

Abou-Khalil, B. (2007). An update on determination of language dominance in screening for epilepsy surgery: the Wada test and newer noninvasive alternatives. Epilepsia 48, 442-455. doi: 10.1111/j.1528-1167.2007.01012.x

Alexander, M. P., and Annett, M. (1996). Crossed aphasia and related anomalies of cerebral organization: Case reports and a genetic hypothesis. Brain Lang. 55, 213-239. doi: 10.1006/brln.1996.0102

Alexander, M. P., Fischette, M. R., and Fischer, R. S. (1989). Crossed aphasias can be mirror image or anomalous. case reports, review and hypothesis. Brain 112, 953-973. doi: 10.1093/brain/112.4.953 
Andelman, F., Kipervasser, S., Reider-Groswasser, I. I., Fried, I., and Neufeld, M. Y. (2006). Hippocampal memory function as reflected by the intracarotid sodium methohexital Wada test. Epilepsy Behav. 9, 579-586. doi: 10.1016/j.yebeh.2006.08.001

Annett, M. (1975). Hand preference and the laterality of cerebral speech. Cortex 11 , 305-328. doi: 10.1016/S0010-9452(75)80024-4

Annett, M. (2000). Predicting combinations of left and right asymmetries. Cortex 36, 485-505. doi: 10.1016/S0010-9452(08)70534-3

Annett, M. (2002). Handedness and Brain Asymmetry: The Right Shift Theory. Hove, East Sussex: Psychology Press.

Armour, J. A., Davison, A., and McManus, I. C. (2013). Genome-wide association study of handedness excludes simple genetic models. Heredity 112, 221-225. doi: 10.1038/hdy.2013.93

Arora, J., Pugh, K., Westerveld, M., Spencer, S., Spencer, D. D., and Todd Constable, R. (2009). Language lateralization in epilepsy patients: fMRI validated with the Wada procedure. Epilepsia 50, 2225-2241. doi: 10.1111/j.15281167.2009.02136.x

Axmacher, N., Bialleck, K. A., Weber, B., Helmstaedter, C., Elger, C. E., and Fell, J. (2009). Working memory representation in atypical language dominance. Hum. Brain Mapp. 30, 2032-2043. doi: 10.1002/hbm.20645

Baciu, M., Juphard, A., Cousin, E., and Bas, J. F. L. (2005). Evaluating fMRI methods for assessing hemispheric language dominance in healthy subjects. Eur. J. Radiol. 55, 209-218. doi: 10.1016/j.ejrad.2004.11.004

Badzakova-Trajkov, G., Häberling, I. S., Roberts, R. P., and Corballis, M. C. (2010). Cerebral asymmetries: complementary and independent processes. PLoS ONE 5:e9682. doi: 10.1371/journal.pone.0009682

Basic, S., Hajnsek, S., Poljakovic, Z., Basic, M., Culic, V., and Zadro, I. (2004). Determination of cortical language dominance using functional transcranial Doppler sonography in left-handers. Clin. Neurophysiol. 115, 154-160. doi: 10.1016/S1388-2457(03)00281-5

Basso, A., Farabola, M., Grassi, M. P., Laiacona, M., and Zanobio, M. E. (1990). Aphasia in left-handers. Comparison of aphasia profiles and language recovery in non-right-handed and matched right-handed patients. Brain Lang. 38, 233-252. doi: 10.1016/0093-934X(90)90113-U

Basso, A., Gardelli, M., Grassi, M. P., and Mariotti, M. (1989). The role of the right hemisphere in recovery from aphasia. Two case studies. Cortex 25, 555-566. doi: 10.1016/S0010-9452(89)80017-6

Basso, A., and Rusconi, M. L. (1998). "Aphasia in left-handers," in Aphasia in Atypical Populations, eds P. Coppens, Y. Lebrun, and A. Basso (Mahwah, NJ: Lawrence Erlbaum Associates), 1-34.

Bauer, P. R., Reitsma, J. B., Houweling, B. M., Ferrier, C. H., and Ramsey, N. F. (2014). Can fMRI safely replace the Wada test for preoperative assessment of language lateralisation? A meta-analysis and systematic review. J. Neurol. Neurosurg. Psychiatry 85, 581-588. doi: 10.1136/jnnp-2013305659

Baxendale, S. (2002). The role of functional MRI in the presurgical investigation of temporal lobe epilepsy patients: a clinical perspective and review. J. Clin. Exper. Neuropsychol. 24, 664-676. doi: 10.1076/jcen.24.5.664.1005

Baxendale, S., Thompson, P. J., and Duncan, J. S. (2008). The role of the Wada test in the surgical treatment of temporal lobe epilepsy: an international survey. Epilepsia 49, 715-720. doi: 10.1111/j.1528-1167.2007.01515_1.x

Baynes, K., and Long, D. L. (2007). Three conundrums of language lateralization. Lang. Linguist Compass 1, 48-70. doi: 10.1111/j.1749-818X.2007. 00006.x

Bellugi, U., Klima, E. S., and Hickok, G. (in press). "Brain organization: clues from deaf signers with left or right hemisphere lesions," in Of Gesture and Word, ed Luis Clara (Lisbon: Editorial Caminho).

Benbadis, S. R., Dinner, D. S., Chelune, G. J., Piedmonte, M., and Luders, H. O. (1995a). Autonomous versus dependent: a classification of bilateral language representation by intracarotid amobarbital procedure. J. Epilepsy 8, 255-263. doi: 10.1016/0896-6974(95)00042-C

Benbadis, S. R., Dinner, D. S., Chelune, G. J., Piedmonte, M., and Lüders, H. O. (1995b). Objective criteria for reporting language dominance by intracarotid amobarbital procedure. J. Clin. Exper. Neuropsychol. 17, 682-690. doi: $10.1080 / 01688639508405158$

Benson, R. R., FitzGerald, D. B., LeSueur, L. L., Kennedy, D. N., Kwong, K. K., Buchbinder, B. R., et al. (1999). Language dominance determined by whole brain functional MRI in patients with brain lesions. Neurology 52, 798-798. doi: 10.1212/WNL.52.4.798
Berl, M. M., Zimmaro, L. A., Khan, O. I., Dustin, I., Ritzl, E., Duke, E. S., et al. (2013). Characterization of atypical language activation patterns in focal epilepsy. Ann. Neurol. 75, 33-42. doi: 10.1002/ana.24015

Berlin, C. I., Hughes, L. F., Lowe-Bell, S. S., and Berlin, H. L. (1973). Dichotic right ear advantage in children 5 to 13 . Cortex 9, 394-402. doi: 10.1016/S00109452(73)80038-3

Bethmann, A., Tempelmann, C., De Bleser, R., Scheich, H., and Brechmann, A (2007). Determining language laterality by fMRI and dichotic listening. Brain Res. 1133, 145-157. doi: 10.1016/j.brainres.2006.11.057

Binder, J. R. (2011). Functional MRI is a valid noninvasive alternative to Wada testing. Epilepsy Behav. 20, 214-222. doi: 10.1016/j.yebeh.2010.08.004

Binder, J. R., Swanson, S. J., Hammeke, T. A., Morris, G. L., Mueller, W. M., Fischer, M., et al. (1996). Determination of language dominance using functional MRI: a comparison with the Wada test. Neurology 46, 978-984. doi: 10.1212/WNL.46.4.978

Bingley, T. (1958). Handedness and Brainedness. In Mental symptoms in temporal lobe epilepsy and temporal lobe gliomas. Acta Psychiatr. Neurol. Scandinavia 33, 136-142.

Bishop, D. V. M. (1980). Measuring familial sinistrality. Cortex 16, 311-313. doi: 10.1016/S0010-9452(80)80067-0

Bishop, D. V. M. (1990). On the futility of using familial sinistrality to subclassify handedness groups. Cortex 26, 153-155. doi: 10.1016/S0010-9452(13)80081-0

Blumstein, S., Goodglass, H., and Tartter, V. (1975). The reliability of ear advantage in dichotic listening. Brain Lang. 2, 226-236. doi: 10.1016/S0093934X(75)80066-6

Bonilha, L., Rorden, C., and Fridriksson, J. (2014). Assessing the clinical effect of residual cortical disconnection after ischemic strokes. Stroke 45, 988-993. doi: 10.1161/STROKEAHA.113.004137

Borenstein, M., Hedges, L. V., Higgins, J. P. T., and Rothstein, H. R. (2008) Introduction to Meta-analysis. Chichester: John Wiley and Sons.

Borenstein, M., Hedges, L. V., Higgins, J. P. T., and Rothstein, H. R. (2010). A basic introduction to fixed-effect and random-effects models for meta-analysis. Res. Synth. Meth. 1, 97-111. doi: 10.1002/jrsm.12

Bosch, V. (2000). Statistical analysis of multi-subject fMRI data: assessment of focal activations. J. Magn. Reson. Imaging 11, 61-64. doi: 10.1002/(SICI)1522-2586 (200001) 11:1<61::AID-JMRI9>3.0.CO;2-C

Boulinguez, P., Velay, J. L., and Nougier, V. (2001). Manual asymmetries in reaching movement control. II: Study of left-handers. Cortex 37, 123-138. doi: 10.1016/S0010-9452(08)70562-8

Brain, W. R. (1945). Speech and handedness. Lancet 246, 837-842. doi: 10.1016/S0140-6736(45)91573-X

Brázdil, M., Zákopčan, J., Kuba, R., Fanfrdlová, Z., and Rektor, I. (2003). Atypical hemispheric language dominance in left temporal lobe epilepsy as a result of the reorganization of language functions. Epilepsy Behav. 4, 414-419. doi: 10.1016/S1525-5050(03)00119-7

Briggs, G. G., and Nebes, R. D. (1976). The effects of handedness, family history and sex on the performance of a dichotic listening task. Neuropsychologia 14, 129-133. doi: 10.1016/0028-3932(76)90014-2

Brown, J. W., and Hécaen, H. (1976). Lateralization and language representation. Observations on aphasia in children, left-handers, and "anomalous" dextrals Neurology 26, 183-189. doi: 10.1212/WNL.26.2.183

Bryden, M. P. (1965). Tachistoscopic recognition, handedness, and cerebral dominance. Neuropsychologia 3, 1-8. doi: 10.1016/0028-3932(65)90015-1

Bryden, M. P. (1982). Laterality: Functional Asymmetry in the Intact Brain. New York, NY: Academic Press.

Bryden, M. P., Free, T., Gagné, S., and Groff, P. (1991). Handedness effects in the detection of dichotically-presented words and emotions. Cortex 27, 229-235. doi: 10.1016/S0010-9452(13)80127-X

Bryden, M. P., Hécaen, H., and DeAgostini, M. (1983a). Patterns of cerebral organisation. Brain Lang. 20, 249-262. doi: 10.1016/0093-934X(83) 90044-5

Bryden, M. P., McManus, I. C., and Bulman-Fleming, M. B. (1994). Evaluating the empirical support for the Geschwind-Behan-Galaburda model of cerebral lateralization. Brain Cogn. 26, 103-167. doi: 10.1006/brcg.1994.1045

Bryden, M. P., Munhall, K., and Allard, F. (1983b). Attentional biases and the rightear effect in dichotic listening. Brain Lang. 18, 236-248. doi: 10.1016/0093934X(83)90018-4

Bryden, P. J., Brown, S. G., Roy, E. A., and Rohr, L. E. (2006). Language lateralization as a function of handedness. Brain Cogn. 60, 306. 
Brysbaert, M. (1994). Interhemispheric transfer and the processing of foveally presented stimuli. Behav. Brain Res. 64, 151-161. doi: 10.1016/01664328(94)90127-9

Brysbaert, M., Cai, Q., and Van der Haegen, L. (2012). "Brain asymmetry and visual word recognition: do we have a split fovea?" in Visual Word Recognition, Vol. 1: Models and Methods, Orthography and Phonology, ed J. S. Adelman (Hove: Psychology Press), 139-158.

Bub, D. N., and Lewine, J. (1988). Different modes of word recognition in the left and right visual fields. Brain Lang. 33, 161-188. doi: 10.1016/0093934X(88)90060-0

Cai, Q., Paulignan, Y., Brysbaert, M., Ibarrola, D., and Nazir, T. A. (2008). The left ventral occipito-temporal response to words depends on language lateralization but not on visual familiarity. Cereb. Cortex 20, 1153-1163. doi: 10.1093/cercor/bhp175

Cai, Q., Van der Haegen, L., and Brysbaert, M. (2013). Complementary hemispheric specialization for language production and visuospatial attention. Proc. Natl. Acad. Sci. U.S.A. 110, E322-E330. doi: 10.1073/pnas. 1212956110

Carey, D. P., and Liddle, J. (2013). Hemifield or hemispace: what accounts for the ipsilateral advantages in visually guided aiming? Exper. Brain Res. 230, 323-331. doi: $10.1007 / \mathrm{s} 00221-013-3657-3$

Carey, D. P., and Otto-de Haart, E. G. (2001). Hemispatial differences in visually guided aiming are neither hemispatial nor visual. Neuropsychologia 39, 885-861. doi: 10.1016/S0028-3932(01)00036-7

Carey, D. P., Smith, D. T., Martin, D., Smith, G., Skriver, J., Rutland, A., et al. (2009). The bi-pedal ape: plasticity and asymmetry in footedness. Cortex 45, 650-661. doi: 10.1016/j.cortex.2008.05.011

Chesher, E. C. (1936). Some observations concerning the relation of handedness to the language mechanism. Bull. Neurol. Ins. N.Y. 4, 556-562.

Chilosi, A. M., Pecini, C., Cipriani, P., Brovedani, P., Brizzolara, D., Ferretti, G., et al. (2005). Atypical language lateralization and early linguistic development in children with focal brain lesions. Dev. Med. Child Neurol. 47, 725-730. doi: $10.1017 /$ S0012162205001532

Chlebus, P., Mikl, M., Brázdil, M., PaŽourková, M., Krupa, P., and Rektor, I. (2007). fMRI evaluation of hemispheric language dominance using various methods of laterality index calculation. Exp. Brain Res. 179, 365-374. doi: 10.1007/s00221006-0794-y

Clarke, J. M., Lufkin, R. B., and Zaidel, E. (1993). Corpus callosum morphometry and dichotic listening performance: individual differences in functional interhemispheric inhibition? Neuropsychologia 31, 547-557. doi: 10.1016/00283932(93) $90051-Z$

Cobianchi, A., and Giaquinto, S. (1998). Positive potentials evoked by the first syllable of spoken words in right-and left-handers. J. Contemp. Neurol. 2-8.

Coppens, P., Hungerford, S., Yamaguchi, S., and Yamadorib, A. (2002). Crossed aphasia: an analysis of the symptoms, their frequency, and a comparison with left-hemisphere aphasia symptomatology. Brain Lang. 83, 425-463. doi: 10.1016/S0093-934X(02)00510-2

Corballis, M. C. (1997). The genetics and evolution of handedness. Psychol. Rev. 104, 714-727. doi: 10.1037/0033-295X.104.4.714

Critchley, M. (1954). Parietal syndromes in ambidextrous and left-handed subjects. Zentralbl. Neurochir. 14, 4-16.

Cumming, G. (2012). Understanding the New Statistics: Effect Sixes, Confidence Intervals and Meta-analysis. New York, NY: Routledge.

Cumming, G. (2013). The new statistics: why and how. Psychol. Sci. 20, 1-23. doi: $10.1177 / 0956797613504966$

Cunningham, J. M., Morris, G. L. III., Drea, L. A., and Kroll, J. L. (2008). Unexpected right hemisphere language representation identified by the intracarotid amobarbital procedure in right-handed epilepsy surgery candidates. Epilepsy Behav. 13, 139-143. doi: 10.1016/j.yebeh.2008.02.019

Curry, F. K. W. (1967). A comparison of left-handed and right-handed subjects on verbal and non-verbal dichotic listening tasks. Cortex 3, 343-352. doi: 10.1016/S0010-9452(67)80022-4

Cuzzocreo, J. L., Yassa, M. A., Verduzco, G., Honeycutt, N. A., David, J., Scott, D. J., et al. (2009). Effect of handedness on fMRI activation in the medial temporal lobe during an auditory verbal memory task. Hum. Brain Mapp. 30, 1271-1278. doi: $10.1002 / \mathrm{hbm} .20596$

Day, L. B., and MacNeilage, P. F. (1996). Postural asymmetries and language lateralization in humans (Homo sapiens). J. Comp. Psychol. 110, 88-96. doi: 10.1037/0735-7036.110.1.88
Deblaere, K., Boon, P. A., Vandemaele, P., Tieleman, A., Vonck, K., Vingerhoets, G., et al. (2004). MRI language dominance assessment in epilepsy patients at 1.0 T: region of interest analysis and comparison with intracarotid amytal testing. Neuroradiology 46, 413-20. doi: 10.1007/s00234-004-1196-0

Dee, H. L. (1971). Auditory asymmetry and strength of manual preference. Cortex 7, 236-245. doi: 10.1016/S0010-9452(71)80003-5

Deeks, J. J., Higgins, J. P. T., and Altman, D. G. (2011). "Analysing data and undertaking meta-analyses," in Cochrane Handbook for Systematic Reviews of Interventions Version 5.1.0), eds J. P. T. Higgins and S. Green The Cochrane Collaboration, Chapter 9. Available online at: www.cochrane-handbook.org.

DeLeon, R., Hiscock, M., and Jansen, B. (2012). Auditory evoked potentials of adults who do or do not show a significant right ear advantage in dichotic listening. Laterality 17, 287-305. doi: 10.1080/1357650X.2011.568489

Dellatolas, G. (1994). Anomalous brain and anomalous model. Brain Cogn. 26, 196-198. doi: 10.1006/brcg.1994.1051

Dellatolas, G., Luciani, S., Castresana, A., Remy, C., Jallon, P., Laplane, D., et al. (1993). Pathological left-handedness: left-handedness correlatives in adult epileptics. Brain 116, 1565-1574. doi: 10.1093/brain/116.6.1565

Dennis, M. (2000). Developmental plasticity in children: the role of biological risk, development, time, and reserve. J. Commun. Disord. 33, 321-332. doi: 10.1016/S0021-9924(00)00028-9

DerSimonian, R., and Laird, N. (1986). Meta-analysis in clinical trials. Control Clin Trials 7, 177-188. doi: 10.1016/0197-2456(86)90046-2

Desmond, J. E., Sum, J. M., and Wagner, A. D. (1995). Functional MRI measurement of language lateralization in Wada-tested patients. Brain 118, 1411-1419. doi: 10.1093/brain/118.6.1411

Dijkstra, K. K., and Ferrier, C. H. (2013). Patterns and predictors of atypical language representation in epilepsy. J. Neurol. Neurosurg. Psychiatry. 84, 379-385. doi: 10.1136/jnnp-2012-303141

Dos Santos Sequeira, S., Woerner, W., Walter, C., Kreuder, F., Lueken, U., Westerhausen, R., et al. (2006). Handedness, dichotic-listening ear advantage, and gender effects on planum temporale asymmetry-a volumetric investigation using structural magnetic resonance imaging. Neuropsychologia 44, 622-636. doi: 10.1016/j.neuropsychologia.2005.06.014

Duffau, H., Capelle, L., Denvil, D., Sichez, N., Gatignol, P., Lopes, M., et al. (2003). Functional recovery after surgical resection of low grade gliomas in eloquent brain: hypothesis of brain compensation. J. Neurol. Neurosurg. Psychiatry 74, 901-907. doi: 10.1136/jnnp.74.7.901

Elias, L. J., Bulman-Fleming, M. B., and Guylee, M. J. (1999a). Complementarity of cerebral function among individuals with atypical laterality profiles. Brain Cogn. 40, 112-115.

Elias, L. J., Bulman-Fleming, M. B., and McManus, I. C. (1999b). Visual temporal asymmetries are related to asymmetries in linguistic perception. Neuropsychologia 37, 1243-1249. doi: 10.1016/S0028-3932(99)00028-7

Eling, P. (1984). Broca on the relation between handedness and cerebral speech dominance. Brain Lang. 22, 158-159. doi: 10.1016/0093-934X(84)90085-3

Emmerich, D. S., Harris, J., Brown, W. S., and Springer, S. P. (1988). The relationship between auditory sensitivity and ear asymmetry on a dichotic listening task. Neuropsychologia 26, 133-143. doi: 10.1016/0028-3932(88)90036-X

Eviatar, Z., Hellige, J. B., and Zaidel, E. (1997). Individual differences in lateralization: effects of gender and handedness. Neuropsychology 11, 562-576. doi: 10.1037/0894-4105.11.4.562

Fedorenko, E., Duncan, J., and Kanwisher, N. (2012a). Language-selective and domain-general regions lie side by side within Broca's area. Curr. Biol. 22, 2059-2062. doi: 10.1016/j.cub.2012.09.011

Fedorenko, E., Hsieh, P. J., Nieto-Castañón, A., Whitfield-Gabrieli, S., and Kanwisher, N. (2010). New method for fMRI investigations of language: defining ROIs functionally in individual subjects. J. Neurophysiol. 104, 1177-1194. doi: $10.1152 /$ jn. 00032.2010

Fedorenko, E., Nieto-Castañon, A., and Kanwisher, N. (2012b). Lexical and syntactic representations in the brain: an fMRI investigation with multi-voxel pattern analyses. Neuropsychologia 50, 499-513. doi: 10.1016/j.neuropsychologia.2011.09.014

Fennell, E. B., Satz, P., and Morris, R. (1983). The development of handedness and dichotic ear listening asymmetries in relation to school achievement: a longitudinal study. J. Exp. Child Psychol. 35, 248-262. doi: 10.1016/00220965(83)90082-6

Fernandes, M. A., and Smith, M. L. (2000). Comparing the fused dichotic words test and the intracarotid amobarbital procedure in children with 
epilepsy. Neuropsychologia 38, 1216-1228. doi: 10.1016/S0028-3932(00) 00035-X

Findlay, A. M., Ambrose, J. B., Cahn-Weiner, D. A., Houde, J. F., Honma, S., Hinkley, L. B., et al. (2012). Dynamics of hemispheric dominance for language assessed by magnetoencephalographic imaging. Ann. Neurol. 71, 668-686. doi: 10.1002/ana.23530

Fleminger, J. J., and Bunce, L. (1975). Investigation of cerebral dominance in 'left-handers' and 'right-handers' using unilateral electroconvulsive therapy. J. Neurol. Neurosurg. Psychiatry 38, 541-545. doi: 10.1136/jnnp.38. 6.541

Flöel, A., Buyx, A., Breitenstein, C., Lohmann, H., and Knecht, S. (2005) Hemispheric lateralization of spatial attention in right-and lefthemispheric language dominance. Behav. Brain Res. 158, 269-275. doi: 10.1016/j.bbr.2004.09.016

Foundas, A. L., Corey, D. M., Hurley, M. M., and Heilman, K. M. (2006). Verbal dichotic listening in right and left-handed adults: laterality effects of directed attention. Cortex 42, 79-86. doi: 10.1016/S0010-9452(08) 70324-1

Gadea, M., Gómez, C., González-Bono, E., Salvador, A., and Espert, R. (2003). Salivary testosterone is related to both handedness and degree of linguistic lateralization in normal women. Psychoneuroendocrinology 28, 274-287. doi: 10.1016/S0306-4530(02)00020-3

Gaillard, W. D., Berl, M. M., Moore, E. N., Ritzl, E. K., Rosenberger, L. R., Weinstein, S. L., et al. (2007). Atypical language in lesional and nonlesional complex partial epilepsy. Neurology 69, 1761-1771. doi: 10.1212/01.wnl.0000289650.48830.1a

Geffen, G., and Caudrey, D. (1981). Reliability and validity of the dichotic monitoring test for language laterality. Neuropsychologia 19, 413-423. doi: 10.1016/00283932(81)90071-3

Geffen, G., and Traub, E. (1980). The effects of duration of stimulation, preferred hand and familial sinistrality in dichotic monitoring. Cortex 16, 83-94. doi: 10.1016/S0010-9452(80)80024-4

Geffen, G., Traub, E., and Stierman, I. (1978). Language laterality assessed by unilateral ECT and dichotic monitoring. J. Neurol. Neurosurg. Psychiatry 41 , 354-360. doi: 10.1136/jnnp.41.4.354

Geschwind, N., and Galaburda, A. M. (1985a). Cerebral lateralization: biological mechanisms, associations, and pathology: I. A hypothesis and a program for research. Arch. Neurol. 42, 428-459. doi: 10.1001/archneur.1985.04060050026008

Geschwind, N., and Galaburda, A. M. (1985b). Cerebral lateralization: biological mechanisms, associations, and pathology: II. A hypothesis and a program for research. Arch. Neurol. 42, 521-552. doi: 10.1001/archneur.1985.04060060019009

Geschwind, N., and Galaburda, A. M. (1985c). Cerebral lateralization: biological mechanisms, associations, and pathology: III. A hypothesis and a program for research. Arch. Neurol. 42, 634-654. doi: 10.1001/archneur.1985.04060070024012

Gloning, I., Gloning, K., Haub, G., and Quatember, R. (1969). Comparison of verbal behavior in right-handed and non right-handed patients with anatomically verified lesion of one hemisphere. Cortex 5, 43-52. doi: 10.1016/S00109452(69)80006-7

Gloning, K. (1977). Handedness and aphasia. Neuropsychologia 15, 355-358. doi: 10.1016/0028-3932(77)90046-X

Godefroy, O., Dubois, C., Debachy, B., Leclerc, M., and Kreisler, A. (2002). Vascular aphasias: main characteristics of patients hospitalized in acute stroke units. Stroke 33, 702-705. doi: 10.1161/hs0302.103653

Goldenberg, G. (2013). Apraxia in left-handers. Brain 136, 2592-2601. doi: $10.1093 /$ brain/awt181

Gonzalez, C. L., and Goodale, M. A. (2009). Hand preference for precision grasping predicts language lateralization. Neuropsychologia 47, 3182-3189. doi 10.1016/j.neuropsychologia.2009.07.019

Gonzalez, C. L., Whitwell, R. L., Morrissey, B., Ganel, T., and Goodale, M. A. (2007). Left handedness does not extend to visually guided precision grasping. Exp. Brain Res. 182, 275-279. doi: 10.1007/s00221-007-1090-1

Goodale, M. A. (1988). Hemispheric differences in motor control. Behav. Brain Res. 30, 203-214. doi: 10.1016/0166-4328(88)90149-0

Goodale, M. A. (1990). "Brain asymmetries in the control of reaching," in Vision and Action: The Control of Grasping, ed M. Goodale (Norwood, NJ: Ablex Publishing), 14-32.
Goodglass, H., and Barton, M. (1963). Handedness and differential perception of verbal stimuli in left and right visual fields. Percept. Mot. Skills 17, 851-854. doi: 10.2466/pms.1963.17.3.851

Goodglass, H., and Quadfasel, F. A. (1954). Language laterality in left-handed aphasics. Brain 77, 521-548. doi: 10.1093/brain/77.4.521

Grimshaw, G. M., McManus, I. C., and Bryden, M. P. (1994). Controlling for stimulus dominance in dichotic listening tests: a modification of $\lambda$. Neuropsychology 8, 278-283. doi: 10.1037/0894-4105.8.2.278

Groen, M. A., Whitehouse, A. J. O., Badcock, N. A., and Bishop, D. V. M. (2013). Associations between handedness and cerebral lateralisation for language: a comparison of three measures in children. PLoS ONE 8:e64876. doi: 10.1371/journal.pone.0064876

Gur, R. C., Gur, R. E., Obrist, W. D., Hungerbuhler, J. P., Younkin, D., Rosen, A. D., et al. (1982). Sex and handedness differences in cerebral blood flow during rest and cognitive activity. Science 217, 659-661. doi: 10.1126/science.7089587

Häberling, I. S., Badzakova-Trajkov, G., and Corballis, M. C. (2011). Callosal tracts and patterns of hemispheric dominance: a combined fMRI and DTI study. Neuroimage 54, 779-786. doi: 10.1016/j.neuroimage.2010.09.072

Haddock, C. K., Rindskopf, D., and Shadish, W. R. (1998). Using odds ratios as effect sizes for meta-analysis of dichotomous data: a primer on methods and issues. Psychol. Meth. 3, 339-353. doi: 10.1037/1082-989X.3.3.339

Hagmann, P., Cammoun, L., Martuzzi, R., Maeder, P., Clarke, S., Thiran, J. P., et al. (2006). Hand preference and sex shape the architecture of language networks Hum. Brain Mapp. 27, 828-835. doi: 10.1002/hbm.20224

Harris, L. J. (1991). Cerebral control for speech in right-handers and left-handers: an analysis of the views of Paul Broca, his contemporaries, and his successors. Brain Lang. 40, 1-50. doi: 10.1016/0093-934X(91)90115-H

Hécaen, H. (1976). Acquired aphasia in children and the ontogenesis of hemispheric functional specialization. Brain Lang. 3, 114-134. doi: 10.1016/0093934X(76)90009-2

Hécaen, H., and de Ajuriaguerra, J. (1964). Left-handedness: Manual Superiority and Cerebral Dominance. New York, NY: Grune and Stratton.

Hécaen, H., and Percy, M. (1956). Paroxysmal dysphasia and the problem of cerebral dominance. J. Neurol. Neurosurg. Psychiatr. 19, 194-201. doi: 10.1136/jnnp.19.3.194

Hécaen, H., and Sauguet, J. (1971). Cerebral dominance in left-handed subjects. Cortex 7, 19-48. doi: 10.1016/S0010-9452(71)80020-5

Heiss, W. D., Kessler, J., Thiel, A., Ghaemi, M., and Karbe, H. (1999). Differential capacity of left and right hemispheric areas for compensation of poststroke aphasia. Ann. Neurol. 45, 430-438.

Hellige, J. B., Bloch, M. I., Cowin, E. L., Eng, T. L., Evitar, Z., and Sergent, V. (1994). Individual variation in hemispheric asymmetry-Multitask study of effects related to handedness and sex. J. Exp. Psychol. Gen. 123, 235-256. doi: 10.1037/0096-3445.123.3.235

Helmstaedter, C. (1999). Sex differences in material-specific cognitive functions related to language dominance: an intracarotid amobarbital study in left temporal lobe epilepsy. Laterality 4, 51-63. doi: 10.1080/713754322

Helmstaedter, C., Kurthen, M., Linke, D. B., and Elger, C. E. (1997). Patterns of language dominance in focal left and right hemisphere epilepsies: relation to MRI findings, EEG, sex, and age at onset of epilepsy. Brain Cogn.33, 135-150. doi: $10.1006 /$ brcg. 1997.0888

Hervé, P. Y., Zago, L., Petit, L., Mazoyer, B., and Tzourio-Mazoyer, N. (2013). Revisiting human hemispheric specialization with neuroimaging. Trends Cogn. Sci. 17, 69-80. doi: 10.1016/j.tics.2012.12.004

Higenbottam, J. A. (1973). Relationships between sets of lateral and perceptual preference measures. Cortex 9, 403-410. doi: 10.1016/S0010-9452(73) 80039-5

Higgins, J. P. T., and Green, S. (2011). Cochrane Handbook for Systematic Reviews of Interventions Version 5.1.0 [updated March 2011]. The Cochrane Collaboration, 2009. Available online at: www.cochrane-handbook.org.

Higgins, J. P. T., and Thompson, S. G. (2004). Controlling the risk of spurious findings from meta-regression. Stat. Med. 23, 1663-1682. doi: 10.1002/sim. 1752

Hines, D., Fennell, E. B., Bowers, D., and Satz, P. (1980). Left-handers show greater test-retest variability. Brain Lang. 10, 208-211. doi: 10.1016/0093934X(80)90050-4

Hinz, A. C., Berger, M. S., Ojemann, G. A., and Dodrill, C. (1994). The utility of the intracarotid Amytal procedure in determining hemispheric speech lateralization in pediatric epilepsy patients undergoing surgery. Childs Nerv. Syst. 10, 239-243. doi: 10.1007/BF00301161 
Hirata, M., Goto, T., Barnes, G., Umekawa, Y., Yanagisawa, T., Kato, A., et al. (2010). Language dominance and mapping based on neuromagnetic oscillatory changes: comparison with invasive procedures: clinical article. J. Neurosurg. 112, 528-538. doi: 10.3171/2009.7.JNS09239

Hirnstein, M., Leask, S., Rose, J., and Hausmann, M. (2010). Disentangling the relationship between hemispheric asymmetry and cognitive performance. Brain $\operatorname{Cogn}$ 73, 119-127. doi: 10.1016/j.bandc.2010.04.002

Hirnstein, M., Westerhausen, R., and Hugdahl, K. (2013). The right planum temporale is involved in stimulus-driven, auditory attention-evidence from transcranial magnetic stimulation. PLoS ONE 8:e57316. doi: 10.1371/journal.pone.0057316

Hiscock, M., Cole, L. C., Benthall, J. G., Carlson, V. L., and Ricketts, J. M. (2000). Toward solving the inferential problem in laterality research: effects of increased reliability on the validity of the dichotic listening right-ear advantage. J. Int. Neuropsychol. Soc. 6, 539-547. doi: 10.1017/S1355617700 655030

Hiscock, M., Inch, R., and Ewing, C. T. (2005). Constant and variable aspects of the dichotic listening right-ear advantage: a comparison of standard and signal detection tasks. Laterality 10, 517-534. doi: 10.1080/1357650044 2000283

Hiscock, M., and Kinsbourne, M. (2011). Attention and the right-ear advantage: what is the connection? Brain Cogn. 76, 263-275. doi: 10.1016/j.bandc.2011.03.016

Hugdahl, K. (1995). "Dichotic listening: probing temporal lobe functional integrity," in Brain Asymmetry, eds R. J. Davidson and K. Hugdahl (Cambridge, MA: MIT Press), 123-156.

Hugdahl, K., and Andersson, L. (1986). The "forced-attention paradigm" in dichotic listening to CV-syllables: a comparison between adults and children. Cortex 22, 417-432. doi: 10.1016/S0010-9452(86)80005-3

Hugdahl, K., and Franzon, M. (1985). Visual half-field presentations of incongruent color-words reveal mirror-reversal of language lateralization in dextral and sinistral subjects. Cortex 21, 359-374. doi: 10.1016/S0010-9452(85) 80002-2

Hugdahl, K., Løberg, E. M., Falkenberg, L. E., Johnsen, E., Kompus, K., Kroken, R. A., et al. (2012). Auditory verbal hallucinations in schizophrenia as aberrant lateralised speech perception: evidence from dichotic listening. Schizophr. Res. 140, 59-64. doi: 10.1016/j.schres.2012.06.019

Hugdahl, K., Westerhausen, R., Alho, K., Medvedev, S., Laine, M., and Hämäläinen, H. (2008). Attention and cognitive control: Unfolding the dichotic listening story. Scand J. Psychol. 50, 11-22. doi: 10.1111/j.1467-9450.2008 00676.x

Humphrey, M. E., and Zangwill, O. L. (1952). Dysphasia in left-handed patients with unilateral brain lesions. J. Neurol. Neurosurg. Psychiatry 15:184. doi: 10.1136/jnnp.15.3.184

Hund-Georgiadis, M., Lex, U., Friederici, A. D., and von Cramon, D. Y. (2002). Non-invasive regime for language lateralization in right- and left-handers by means of functional MRI and dichotic listening. Exp. Brain Res. 145, 166-176. doi: 10.1007/s00221-002-1090-0

Isaacs, K. L., Barr, W. B., Nelson, P. K., and Devinsky, O. (2006). Degree of handedness and cerebral dominance. Neurology 66, 1855-1858. doi 10.1212/01.wnl.0000219623.28769.74

Jäncke, L. (1993). Do ear advantage scores obtained in a consonant-vowel recall test vary with respect to the required response condition? Neuropsychologia 31 , 499-501. doi: 10.1016/0028-3932(93)90063-6

Jansen, A., Lohmann, H., Scharfe, S., Sehlmeyer, C., Deppe, M., and Knecht, S. (2007). The association between scalp hair-whorl direction, handedness and hemispheric language dominance: is there a common genetic basis of lateralization? Neuroimage 35, 853-861. doi: 10.1016/j.neuroimage.2006.12.025

Jansen, A., Menke, R., Sommer, J., Förster, A. F., Bruchmann, S., Hempleman, J., et al. (2006). The assessment of hemispheric lateralization in functional MRI-Robustness and reproducibility. Neuroimage 33, 204-217. doi: 10.1016/j.neuroimage.2006.06.019

Jones, S. E., Mahmoud, S. Y., and Phillips, M. D. (2011). A practical clinical method to quantify language lateralization in fMRI using whole-brain analysis. Neuroimage 54, 2937-2949. doi: 10.1016/j.neuroimage.2010.10.052

Kadis, D. S., Pang, E. W., Mills, T., Taylor, M. J., McAndrews, M. P., and Smith, M. L. (2011). Characterizing the normal developmental trajectory of expressive language lateralization using magnetoencephalography. J. Int. Neuropsychol. Soc. 7, 896-904. doi: 10.1017/S1355617711000932
Kanai, R., and Rees, G. (2011). The structural basis of inter-individual differences in human behaviour and cognition. Nat. Rev. Neurosci. 12, 231-242. doi: $10.1038 / \mathrm{nrn} 3000$

Kanwisher, N. (1997). The fusiform face area: a module in human extrastriate cortex specialised for face perception. J. Neurosci. 17, 4302-4311.

Khedr, E. M., Hamed, E., Said, A., and Basahi, J. (2002). Handedness and language cerebral lateralization. Eur. J. Appl. Physiol. 87, 469-473. doi: 10.1007/s00421002-0652-y

Kim, H. (1994). Distributions of hemispheric asymmetry in left-handers and righthanders: data from perceptual asymmetry studies. Neuropsychology 8, 148-159. doi: 10.1037/0894-4105.8.2.148

Kim, H., and Levine, S. C. (1991). Inferring patterns of hemispheric specialization for individual subjects from laterality data: a two-task criterion. Neuropsychologia 29, 93-105. doi: 10.1016/0028-3932(91)90095-P

Kim, H., Yi, S., Son, E. I., and Kim, J. (2001). Evidence for the pathological right-handedness hypothesis. Neuropsychology 15, 510-515. doi: 10.1037/08944105.15.4.510

Kimura, D. (1961). Cerebral dominance and the perception of verbal stimuli. Can. J. Psychol. 15, 166. doi: 10.1037/h0083219

Kimura, D. (1973a). Manual activity during speaking: I. Right-handers. Neuropsychologia 11, 45-50. doi: 10.1016/0028-3932(73)90063-8

Kimura, D. (1973b). Manual activity during speaking: II. Left-handers. Neuropsychologia 11, 51-55. doi: 10.1016/0028-3932(73)90064-X

Kimura, D. (1983). Speech representation in an unbiased sample of left-handers. Hum. Neurobiol. 2, 147-154.

Kimura, D. (1993). Neuromotor Mechanisms in Human Communication. Oxford: Oxford University Press.

Klar, A. J. S. (2003). Human handedness and scalp hair-whorl direction develop from a common genetic mechanism. Genetics 165, 269-276.

Knake, S., Haag, A., Hamer, H. M., Dittmer, C., Bien, S., Oertel, W. H., et al. (2003). Language lateralization in patients with temporal lobe epilepsy: a comparison of functional transcranial Doppler sonography and the Wada test. Neuroimage 19,1228-1232. doi: 10.1016/S1053-8119(03)00174-5

Knecht, S., Deppe, M., Ebner, A., Henningsen, H., Huber, T., Jokeit, H., et al. (1998). Noninvasive determination of language lateralization by functional transcranial Doppler sonography a comparison with the Wada test. Stroke 29, 82-86. doi: 10.1161/01.STR.29.1.82

Knecht, S., Dräger, B., Deppe, M., Bobe, L., Lohmann, H., Flöel, A., et al. (2000) Handedness and hemispheric language dominance in healthy humans. Brain 123, 2512-2518. doi: 10.1093/brain/123.12.2512

Kompus, K., Specht, K., Ersland, L., Juvodden, H. T., van Wageningen, H., Hugdahl, K., et al. (2012). A forced-attention dichotic listening fMRI study on 113 subjects. Brain Lang. 121, 240-247. doi: 10.1016/j.bandl.2012. 03.004

Krach, S., Chen, L. M., and Hartje, W. (2006). Comparison between visual halffield performance and cerebral blood flow changes as indicators of language dominance. Laterality 11, 122-140. doi: 10.1080/13576500500384975

Krieg, S. M., Sollmann, N., Hauck, T., Ille, S., Foerschler, A., Meyer, B., et al. (2013). Functional language shift to the right hemisphere in patients with languageeloquent brain tumors. PLOS ONE 8:e75403. doi: 10.1371/journal.pone. 0075403

Kurthen, M., Helmstaedter, C., Linke, D. B., Hufnagel, A., Elger, C. E., and Schramm, J. (1994). Quantitative and qualitative evaluation of patterns of cerebral language dominance. Brain Lang. 46, 536-564. doi: 10.1006/brln. 1994.1030

Laska, A. C., Hellblom, A., Murray, V., Kahan, T., and Von Arbin, M. (2001). Aphasia in acute stroke and relation to outcome. J. Intern. Med. 249, 413-422. doi: 10.1046/j.1365-2796.2001.00812.x

Levy, J. (1974). "Psychobiological implications of bilateral asymmetry," in Hemisphere Function in the Human Brain, eds S. J. Dimond and J. G. Beaumont (London: Elek Science), 121-183.

Lieberman, P. (2006). Toward an Evolutionary Biology of Language. Cambridge: Harvard University Press.

Lindell, A. K., and Nicholls, M. E. R. (2003). Attentional deployment in visual halffield tasks: the effect of cue position on word naming latency. Brain Cogn. 53, 273-277. doi: 10.1016/S0278-2626(03)00125-8

Lishman, W. A., and McMeekan, E. R. L. (1977). Handedness in relation to direction and degree of cerebral dominance for language. Cortex 13, 30-43. doi: 10.1016/S0010-9452(77)80051-8 
Lomas, J., and Kimura, D. (1976). Intrahemispheric interaction between speaking and sequential manual activity. Neuropsychologia 14, 23-33. doi: 10.1016/00283932(76)90004-X

Loring, D. W., Meador, K. J., Lee, G. P., Murro, A. M., Smith, J. R., Flanigin, H. F., et al. (1990). Cerebral language lateralization: evidence from intracarotid amobarbital testing. Neuropsychologia 28, 831-838. doi: 10.1016/0028-3932(90) 90007-B

Luria, A. R. (1970). Traumatic Aphasia: Its Syndromes, Psychology and Treatment. Mouton: The Hague.

MacNeilage, P. F. (2008). The Origin of Speech. Studies in the Evolution of Language, No. 10. Oxford: Oxford University Press.

Mbwana, J., Berl, M. M., Ritzl, E. K., Rosenberger, L., Mayo, J., Weinstein, S., et al. (2009). Limitations to plasticity of language network reorganization in localization related epilepsy. Brain 132, 347-356. doi: 10.1093/brain/awn329

McGlone, J. (1977). Sex differences in the cerebral organization of verbal functions in patients with unilateral brain lesions. Brain 100, 775-793. doi: 10.1093/brain/100.4.775

McGlone, J., and Davidson, W. (1973). The relation between cerebral speech laterality and spatial ability with special reference to sex and hand preference. Neuropsychologia 11, 105-113. doi: 10.1016/0028-3932(73) 90070-5

McKeever, W. F. (1979). Handwriting posture in left-handers: sex, familial sinistrality and language laterality correlates. Neuropsychologia 17, 429-444. doi: 10.1016/0028-3932(79)90050-2

McKeever, W. F., and Jackson, T. L. Jr. (1979). Cerebral dominance assessed by object-and color-naming latencies: Sex and familial sinistrality effects. Brain Lang 7, 175-190. doi: 10.1016/0093-934X(79)90015-4

McKeever, W. F., Nolan, D. R., Diehl, J. A., and Seitz, K. S. (1984). Handedness and language laterality: discrimination of handedness groups on the dichotic consonant-vowel task. Cortex 20, 509-523. doi: 10.1016/S0010-9452(84) 80054-4

McKeever, W. F., and VanDeventer, A. D. (1977). Visual and auditory language processing asymmetries: influences of handedness, familial sinistrality, and sex. Cortex 13, 225-241. doi: 10.1016/S0010-9452(77)80033-6

McKeever, W. F., Van Deventer, A. D., and Suberi, M. (1973). Avowed, assessed, and familial handedness and differential hemispheric processing of brief sequential and non-sequential visual stimuli. Neuropsychologia 11, 235-238. doi: 10.1016/0028-3932(73)90013-4

McManus, I. C. (1985). Right- and left-hand skill: failure of the right shift model. Br. J. Psychol. 76, 1-16. doi: 10.1111/j.2044-8295.1985.tb01926.x

McManus, I. C. (2002). Right Hand, Left Hand: The Origins of Asymmetry in Brains, Bodies, Atoms and Cultures. London: Weidenfeld and Nicolson.

Medina, L. S., Bernal, B., and Ruiz, J. (2007). Role of functional MR in determining language dominance in epilepsy and nonepilepsy populations: a Bayesian analysis. Radiology 242, 94-100. doi: 10.1148/radiol.2421050677

Meng, M., Cherian, T., Singal, G., and Sinha, P. (2012). Lateralization of face processing in the human brain. Proc. R. Soc. B Biol. Sci. 279, 2052-2061. doi 10.1098/rspb.2011.1784

Mieschke, P. E., Elliott, D., Helsen, W. F., Carson, R. G., and Coull, J. A. (2001). Manual asymmetries in the preparation and control of goal-directed movements. Brain Cogn. 45, 129-140. doi: 10.1006/brcg.2000.1262

Miller, J. W., Jayadev, S., Dodrill, C. B., and Ojemann, G. A. (2005). Gender differences in handedness and speech lateralization related to early neurologic insults. Neurology 65, 1974-1975. doi: 10.1212/01.wnl.0000188900.91741.ea

Möddel, G., Lineweaver, T., Schuele, S. U., Reinholz, J., and Loddenkemper, T. (2009). Atypical language lateralization in epilepsy patients. Epilepsia 50, 1505-1516. doi: 10.1111/j.1528-1167.2008.02000.x

Moffat, S. D., and Hampson, E. (2000a). Salivary testosterone concentrations in left-handers: An association with cerebral language lateralization. Neuropsychology 14, 71-81. doi: 10.1037/0894-4105.14.1.71

Moffat, S. D., and Hampson, E. (2000b). Salivary testosterone levels in left and right-handed adults. Neuropsychologia 34, 225-233. doi: 10.1016/00283932(95)00090-9

Murphy, K., and Peters, M. (1994). Right-handers and left-handers show differences and important similarities in task integration when performing manual and vocal tasks concurrently. Neuropsychologia 32, 663-674. doi: 10.1016/00283932(94)90027-2

Neville, H. J., Bavelier, D., Corina, D., Rauschecker, J., Karni, A., Lalwani, A., et al. (1998). Cerebral organization for language in deaf and hearing subjects: biological constraints and effects of experience. Proc. Natl. Acad. Sci. U.S.A. 95, 922-929. doi: 10.1073/pnas.95.3.922

Newcombe, F., and Ratcliff, G. (1973). Handedness, speech lateralization and ability. Neuropsychologia 11, 399-407. doi: 10.1016/0028-3932(73)90026-2

Niskanen, E., Könönen, M., Villberg, V., Nissi, M., Ranta-Aho, P., Säisänen, L., et al. (2012). The effect of fMRI task combinations on determining the hemispheric dominance of language functions. Neuroradiology 54, 393-405. doi: 10.1007/s00234-011-0959-7

Obrzut, J. E., Conrad, P. F., Bryden, M. P., and Boliek, C. A. (1988). Cued dichotic listening with right-handed, left-handed, bilingual and learningdisabled children. Neuropsychologia 26, 119-131. doi: 10.1016/0028-3932(88) 90035-8

Ocklenburg, S., Beste, C., Arning, L., Peterburs, J., and Güntürkün, O. (2014). The ontogenesis of language lateralization and its relation to handedness. Neurosci. Biobehav. Rev. 43, 191-198. doi: 10.1016/j.neubiorev.2014.04.008

Ocklenburg, S., Hugdahl, K., and Westerhausen, R. (2013). Structural white matter asymmetries in relation to functional asymmetries during speech perception and production. Neuroimage 83, 1088-1097. doi: 10.1016/j.neuroimage.2013.07.076

Orbach, J. (1967). Differential recognition of Hebrew and English words in right and left visual fields as a function of cerebral dominance and reading habits Neuropsychologia 5, 127-134. doi: 10.1016/0028-3932(67)90014-0

Orsini, D. L., Satz, P., Soper, H. V., and Light, R. K. (1985). The role of familial sinistrality in cerebral organization. Neuropsychologia 23, 223-232. doi: 10.1016/0028-3932(85)90106-X

Papadatou-Pastou, M., Martin, M., Munafo, M. R., and Jones, G. V. (2008). Sex differences in left-handedness: a meta-analysis of 144 studies. Psychol. Bull. 134, 677-699. doi: 10.1037/a0012814

Parker, G. J. M., Luzzi, S., Alexander, D. C., Wheeler-Kingshott, C. A. M., Ciccarelli, O., and Lambon Ralph, M. A. (2005). Lateralization of ventral and dorsal auditory-language pathways in the human brain. Neuroimage 24, 656-666. doi: 10.1016/j.neuroimage.2004.08.047

Passow, S., Westerhausen, R., Hugdahl, K., Wartenburger, I., Heekeren, H. R., Lindenberger, U., et al. (2014). Electrophysiological correlates of adult age differences in attentional control of auditory processing. Cereb. Cortex 24, 249-60. doi: 10.1093/cercor/bhs306

Pedersen, P. M., Jørgensen, H. S., Nakayama, H., Raaschou, H. O., and Olsen, T. S. (1995). Aphasia in acute stroke: incidence, determinants, and recovery. Ann. Neurol. 38, 659-666. doi: 10.1002/ana.410380416

Pedersen, P. M., Vinter, K., and Olsen, T. S. (2004). Aphasia after stroke: type, severity and prognosis. The Copenhagen aphasia study. Cerebrovasc Dis. 17, 35-43. doi: $10.1159 / 000073896$

Perlaki, G., Horvath, R., Orsi, G., Aradi, M., Auer, T., Varga, E., et al. (2013). Whitematter microstructure and language lateralization in left-handers: a whole-brain MRI analysis. Brain Cogn. 82, 319-328. doi: 10.1016/j.bandc.2013.05.005

Peters, M. (1996). "Hand performance and preference in left handers," in Manual Asymmetries in Motor Performance, eds D. Elliot and E. A. Roy (Boca Raton, FL: CRC Press), 99-120.

Pettit, J. M., and Noll, J. D. (1979). Cerebral dominance in aphasia recovery. Brain Lang. 7, 191-200. doi: 10.1016/0093-934X(79)90016-6

Pillai, J. J., and Zaca, D. (2011). Relative utility for hemispheric lateralization of different clinical fMRI activation tasks within a comprehensive language paradigm battery in brain tumor patients as assessed by both threshold-dependent and threshold-independent analysis methods. Neuroimage 54, S136-S145. doi: 10.1016/j.neuroimage.2010.03.082

Powell, G. E., Polkey, C. E., and Canavan, A. G. (1987). Lateralisation of memory functions in epileptic patients by use of the sodium amytal (Wada) technique. J. Neurol. Neurosurg. Psychiatry 50, 665-672. doi: 10.1136/jnnp.50.6.665

Powell, J. L., Kemp, G. J., and García-Finaña, M. (2012). Association between language and spatial laterality and cognitive ability: an fMRI study. Neuroimage 59, 1818-1829. doi: 10.1016/j.neuroimage.2011.08.040

Pratt, R. T. C., and Warrington, E. K. (1972). The assessment of cerebral dominance with unilateral E.C.T. Br. J. Psychiatry 121, 327-328. doi: 10.1192/bjp.121.3.327

Pujol, J., Deus, J., Losilla, J. M., and Capde Vila, A. (1999). Cerebral lateralization of language in normal left handed people studied by functional fMRI. Neurology 52, 1038-1043. doi: 10.1212/WNL.52.5.1038

Raja Beharelle, A., Dick, A. S., Josse, G., Solodkin, A., Huttenlocher, P. R., Levine, S. C., et al. (2010). Left hemisphere regions are critical for language in the face of early left focal brain injury. Brain 133, 1707-1716. doi: 10.1093/brain/awq104 
Rasmussen, T., and Milner, B. (1977). The role of early left-brain injury in determining lateralization of cerebral speech functions. Ann. N.Y. Acad. Sci. 299, 355-369. doi: 10.1111/j.1749-6632.1977.tb41921.x

Review Manager (RevMan) [Computer program]. (2008). Version 5.0. Copenhagen: The Nordic Cochrane Centre, The Cochrane Collaboration.

Rey, M., Dellatolas, G., Bancaud, J., and Talairach, J. (1988). Hemispheric lateralization of motor and speech functions after early brain lesion: study of 73 epileptic patients with intracarotid amytal test. Neuropsychologia 26, 167-172. doi: 10.1016/0028-3932(88)90040-1

Risse, G. L., Gates, J. R., and Fangman, M. C. (1997). A reconsideration of bilateral language representation based on the intracarotid amobarbital procedure. Brain Cogn. 33, 118-132. doi: 10.1006/brcg.1997.0887

Ross, E. D., and Monnot, M. (2008). Neurology of affective prosody and its functional-anatomic organization in right hemisphere. Brain Lang. 104, 51-74. doi: 10.1016/j.bandl.2007.04.007

Rossi, G. F., and Rosadini, G. (1967). "Experimental analysis of cerebral dominance in man," in Brain Mechanisms Underlying Speech and Language, eds C. H. Millikan and F. I. Darley (London: Grune and Stratton), 167-184.

Sabbah, P., Chassoux, F., Leveque, C., Landre, E., Baudoin-Chial, S., Devaux, B., et al. (2003). Functional MR imaging in assessment of language dominance in epileptic patients. Neuroimage 18, 460-467. doi: 10.1016/S1053-8119(03) 00025-9

Satz, P. (1979). A test of some models of hemispheric speech organization in the left-and right-handed. Science 203, 1131-1133. doi: 10.1126/science.424744

Satz, P., Achenbach, K., Pattishall, E., and Fennell, E. (1965). Order of report, ear asymmetry and handedness in dichotic listening. Cortex 1, 377-396. doi: 10.1016/S0010-9452(65)80001-6

Schmidt, F. L., and Hunter, J. E. (2015). Methods of Meta-analysis: Correcting Error and Bias in Research Findings. London: Sage

Searleman, A., and Porac, C. (2003). Lateral preference profiles and right shift attempt histories of consistent and inconsistent left-handers. Brain Cogn. 52, 175-180. doi: 10.1016/S0278-2626(03)00053-8

Seghier, M. L. (2008). Laterality index in functional MRI: methodological issues. Magn. Reson. Imaging 26, 594-601. doi: 10.1016/j.mri.2007.10.010

Serafetinides, E. A., Hoare, R. D., and Driver, M. V. (1965). Intracarotid sodium amylobarbitone and cerebral dominance for speech and consciousness. Brain 88, 107-130. doi: 10.1093/brain/88.1.107

Shapleske, J., Rossell, S. L., Woodruff, P. W. R., and David, A. S. (1999). The planum temporale: a systematic, quantitative review of its structural, functional and clinical significance. Brain Res. Rev. 29, 26-49. doi: 10.1016/S01650173(98)00047-2

Siebner, H. R., Limmer, C., Peinemann, A., Drzezga, A., Bloem, B. R., Schwaiger M., et al. (2002). Long-term consequences of switching handedness: A positron emission tomography study on handwriting in "converted" left-handers. J. Neurosci. 22, 2816-2825.

Slezicki, K. I., Cho, Y. W., Yi, S. D., Brock, M. S., Pfeiffer, M. H., McVearry, K. M., et al. (2009). Incidence of atypical handedness in epilepsy and its association with clinical factors. Epilepsy Behav. 16, 330-334. doi: 10.1016/j.yebeh.2009.08.006

Snyder, P. J., and Harris, L. J. (1997). The intracarotid amobarbital procedure: an historical perspective. Brain Cogn. 33, 18-32. doi: 10.1006/brcg.1997. 0882

Snyder, P. J., Novelly, R. A., and Harris, L. J. (1990). Mixed speech dominance in the intracarotid sodium amytal procedure: validity and criteria Issues. J. Clin. Exp. Neuropsychol. 12, 629-643. doi: 10.1080/01688639008401007

Spreer, J., Arnold, S., Quiske, A., Wohlfarth, R., Ziyeh, S., Altenmüller, D., et al. (2002). Determination of hemisphere dominance for language: comparison of frontal and temporal fMRI activation with intracarotid amytal testing. Neuroradiology 44, 467-474. doi: 10.1007/s00234-002-0782-2

Springer, J. A., Binder, J. R., Hammeke, T. A., Swanson, S. J., Frost, J. A., Bellgowan, P. S., et al. (1999). Language dominance in neurologically normal and epilepsy subjects: a functional MRI study. Brain 122, 2033-2046. doi: 10.1093/brain/122.11.2033

Springer, S. P., and Searleman. (in press). "A. Left-handedness in twins: implications for the mechanisms underlying cerebral asymmetry of function," in Neuropsychology of Left Handedness, ed J. Herron (New York, NY: Academic Press), 139-158.

Staudt, M., Lidzba, K., Grodd, W., Wildgruber, D., Erb, M., and KragelohMann, I. (2002). Right-hemispheric organization of language following early left-sided brain lesions: functional MRI topography. Neuroimage 16, 954-967. doi: 10.1006/nimg.2002.1108

Stennis Watson, G., Pusakulich, R. L., Ward, J. P., and Hermann, B. (1998). Handedness, footedness, and language laterality: evidence from Wada testing. Laterality 3, 323-330. doi: 10.1080/713754311

Stewart, C. C., Swanson, S. J., Sabsevitz, D. S., Rozman, M. E., Janecek, J. K., and Binder, J. R. (2014). Predictors of language lateralization in temporal lobe epilepsy. Neuropsychologia 60, 93-102. doi: 10.1016/j.neuropsychologia.2014.05.021

Strauss, E. (1986). Hand, foot, eye and ear preferences and performance on a dichotic listening test. Cortex 22, 475-482. doi: 10.1016/S0010-9452(86) 80009-0

Strauss, E., Gaddes, W. H., and Wada, J. (1987). Performance on a free-recall verbal dichotic listening task and cerebral dominance determined by the carotid amytal test. Neuropsychologia 25, 747-753. doi: 10.1016/0028-3932(87) 90112-6

Strauss, E., Satz, P., and Wada, J. (1990). An examination of the crowding hypothesis in epileptic patients who have undergone the carotid amytal test. Neuropsychologia 28, 1221-1227. doi: 10.1016/0028-3932(90)90057-U

Strauss, E., and Wada, J. (1983). Lateral preferences and cerebral speech dominance. Cortex 19, 165-177. doi: 10.1016/S0010-9452(83)80012-4

Subirana, A. (1969). "Handedness and cerebral dominance," in Handbook of Clinical Neurology, eds P. Vinken and G. Bruyn (Amsterdam), 248-272.

Sussman, H. M. (1982). Contrastive patterns of intrahemispheric interference to verbal and spatial concurrent tasks in right-handed, left-handed and stuttering populations. Neuropsychologia 20, 675-684. doi: 10.1016/00283932(82)90067-7

Sveller, C., Briellmann, R. S., Saling, M. M., Lillywhite, L., Abbott, D. F., Masterton, R. A. J., et al. (2006). Relationship between language lateralization and handedness in left-hemispheric partial epilepsy. Neurology 67, 1813-1971. doi: 10.1212/01.wnl.0000244465.74707.42

Szaflarski, J. P., Binder, J. R., Possing, E. T., McKiernan, K. A., Ward, B. D. and Hammeke, T. A. (2002). Language lateralization in left-handed and ambidextrous people: fMRI data. Neurology 59, 238-244. doi: 10.1212/WNL.59. 2.238

Szaflarski, J. P., Rajagopal, A., Altaye, M., Byars, A. W., Jacola, L., Schmithorst, V. J., et al. (2012). Left-handedness and language lateralization in children. Brain Res. 1433, 85-97. doi: 10.1016/j.brainres.2011.11.026

Tzourio-Mazoyer, N., Marie, D., Zago, L., Jobard, G., Perchey, G., Leroux, G., et al (2014). Heschl's gyrification pattern is related to speech-listening hemispheric lateralization: fMRI investigation in 281 healthy volunteers. Brain Struct. Funct. doi: 10.1007/s00429-014-0746-4. [Epub ahead of print]

Van der Haegen, L., Cai, Q., Stevens, M. A., and Brysbaert, M. (2013a) Interhemispheric communication influences reading behavior. J. Cogn. Neurosci. 25, 1442-1452. doi: 10.1162/jocn_a_00412

Van der Haegen, L., Westerhausen, R., Hugdahl, K., and Brysbaert, M. (2013b). Speech dominance is a better predictor of functional brain asymmetry than handedness: a combined fMRI word generation and behavioural dichotic listening study. Neuropsychologia 51, 91-97. doi: 10.1016/j.neuropsychologia.2012.11.002

Van der Kallen, B. F., Morris, G. L., Yetkin, F. Z., Van Erning, L. J., Thijssen, H. O., and Haughton, V. M. (1998). Hemispheric language dominance studied with functional MR: preliminary study in healthy volunteers and patients with epilepsy. Am. J. Neuroradiol. 19, 73-77.

van Rijn, S., Aleman, A., van Diessen, E., Berckmoes, C., Vingerhoets, G., and Kahn, R. S. (2005). What is said or how it is said makes a difference: role of the right fronto-parietal operculum in emotional prosody as revealed by repetitive TMS. Eur. J. Neurosci. 21, 3195-3200. doi: 10.1111/j.1460-9568.2005 04130.x

Vargha-Khadem, F., O'Gorman, A. M., and Watters, G. V. (1985). Aphasia and handedness in relation to hemispheric side, age at injury and severity of cerebral lesion during childhood. Brain 108, 677-696. doi: 10.1093/brain/ 108.3.677

Vernooij, M. W., Smits, M., Wielopolski, P. A., Houston, G. C., Krestin, G. P., and van der Lugta, A. (2007). Fiber density asymmetry of the arcuate fasciculus in relation to functional hemispheric language lateralization in both right- and left-handed healthy subjects: a combined fMRI and DTI study. Neuroimage 35, 1064-1076. doi: 10.1016/j.neuroimage.2006.12.041 
Vigneau, M., Beaucousin, V., Hervé, P. Y., Jobard, G., Petit, L., Crivello, F, et al. (2011). What is right-hemisphere contribution to phonological, lexico-semantic, and sentence processing?: insights from a meta-analysis. Neuroimage 54, 577-593. doi: 10.1016/j.neuroimage.2010. 07.036

Vogel, E. K., and Awh, E. (2008). How to exploit diversity for scientific gain using individual differences to constrain cognitive theory. Curr. Dir. Psychol. Sci. 17, 171-176. doi: 10.1111/j.1467-8721.2008.00569.x

Voyer, D., and Ingram, J. D. (2005). Attention, reliability, and validity of perceptual asymmetries in the fused dichotic words test. Laterality 10, 545-561. doi: $10.1080 / 13576500442000292$

Wada, J. A. (1997). Youthful season revisited. Brain Cogn., 33, 7-10. doi: 10.1006/brcg.1997.0879

Wade, D. T., Hewer, R. L., David, R. M., and Enderby, P. M. (1986). Aphasia after stroke: natural history and associated deficits. J. Neurol. Neurosurg. Psychiatry 49, 11-16. doi: 10.1136/jnnp.49.1.11

Wagner, K., Hader, C., Metternich, B., Buschmann, F., Schwarzwald, R., and Schulze-Bonhage, A. (2012). Who needs a Wada test? Present clinical implications for amobarbital procedures. J. Neurol. Neurosurg. Psychiatry 83, 503-509. doi: 10.1136/jnnp-2011-300417

Wang, A., Peters, T. M., de Ribaupierre, S., and Mirsattari, S. M. (2012). Functional magnetic resonance imaging for language mapping in temporal lobe epilepsy. Epilepsy Res. Treat. 2012:198183. doi: 10.1155/2012/198183

Wang, J., You, X., Wu, W., Guillen, M. R., Cabrerizo, M., Sullivan, J., et al. (2013). Classification of fMRI patterns-A study of the language network segregation in pediatric localization related epilepsy. Hum. Brain Mapp. 35, 1446-1460. doi: 10.1002/hbm.22265

Warrington, E. K., and Pratt, R. T. C. (1973). Language laterality in left-handers assessed by unilateral ECT. Neuropsychologia 11, 423-428. doi: 10.1016/00283932(73)90029-8

Warrington, E. K., and Pratt, R. T. C. (1981). The significance of laterality effects. J. Neurol. Neurosurg. Psychiatry 44, 193-196. doi: 10.1136/jnnp. 44.3.193

Westerhausen, R., Kreuder, F., Dos Santos Sequeira, S., Walter, C., Woerner, W., Wittling, R. A., et al. (2006). The association of macro- and microstructure of the corpus callosum and language lateralisation. Brain Lang. 97, 80-90. doi: 10.1016/j.bandl.2005.07.133

Wexler, B. E., and Halwes, T. (1983). Increasing the power of dichotic methods: the fused rhymed words test. Neuropsychologia 21, 59-66. doi: 10.1016/00283932(83)90100-8
Whitehouse, A. J., and Bishop, D. V. (2009). Hemispheric division of function is the result of independent probabilistic biases. Neuropsychologia 47, 1938-1943. doi: 10.1016/j.neuropsychologia.2009.03.005

Willems, R. M., Van der Haegen, L., Fisher, S. E., and Francks, C. (2014). On the other hand: including left-handers in cognitive neuroscience and neurogenetics. Nat. Rev. Neurosci. 15, 193-201. doi: 10.1038/nrn3679

Woods, R. P., Dodrill, C. B., and Ojemann, G. A. (1988). Brain injury, handedness, and speech lateralization in a series of amobarbital studies. Ann. Neurol. 23, 510-518. doi: 10.1002/ana.410230514

Worthington, C., Vincent, D. J., Bryant, A. E., Roberts, D. R.,Vera, C. L., Ross, D. A., et al. (1997). Comparison of functional magnetic resonance imaging for language localization and intracarotid speech amytal testing in presurgical evaluation for intractable epilepsy. Preliminary results. Stereotac. Funct. Neurosurg. 69, 197-201. doi: 10.1159/000099874

Yeo, R. A., and Gangstead, S. W. (1993). Developmental origins of variations in human hand preference. Genetica 89, 281-296. doi: 10.1007/BF02424521

Yovel, G., Tambini, A., and Brandman, T. (2008). The asymmetry of the fusiform face area is a stable individual characteristic that underlies the left-visual-field superiority for faces. Neuropsychologia 46, 3061-3068. doi: 10.1016/j.neuropsychologia.2008.06.017

Zangwill, O. L. (1960). Cerebral Dominance and its Relation to Psychological Function. Oxford: England.

Conflict of Interest Statement: The authors declare that the research was conducted in the absence of any commercial or financial relationships that could be construed as a potential conflict of interest.

Received: 31 January 2014; accepted: 16 September 2014; published online: 04 November 2014.

Citation: Carey DP and Johnstone LT (2014) Quantifying cerebral asymmetries for language in dextrals and adextrals with random-effects meta analysis. Front. Psychol. 5:1128. doi: 10.3389/fpsyg.2014.01128

This article was submitted to Cognition, a section of the journal Frontiers in Psychology.

Copyright (c) 2014 Carey and Johnstone. This is an open-access article distributed under the terms of the Creative Commons Attribution License (CC BY). The use, distribution or reproduction in other forums is permitted, provided the original author(s) or licensor are credited and that the original publication in this journal is cited, in accordance with accepted academic practice. No use, distribution or reproduction is permitted which does not comply with these terms. 